\title{
Preliminary Technique Assessment for Nondestructive Evaluation Certification of the NNWSI Disposal Container Closure
}

\author{
Robert A. Day \\ Engineering Sciences Division
}

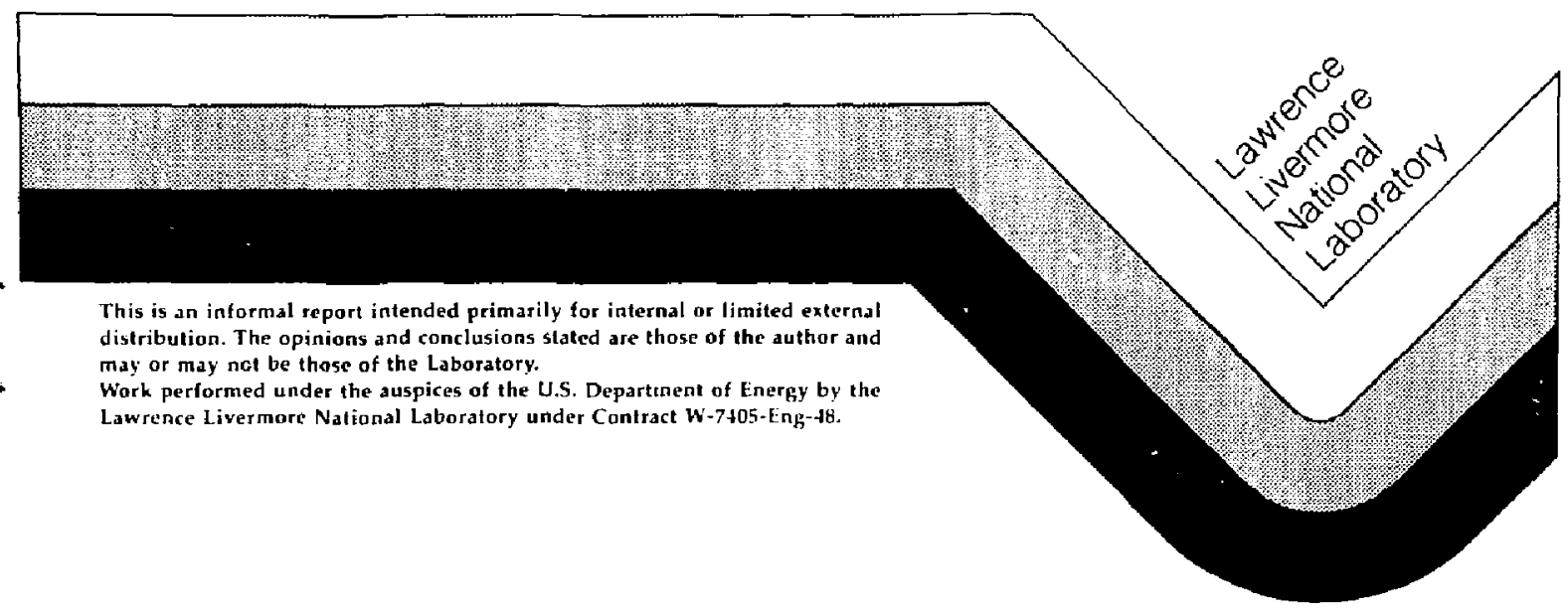


This document was prepared as an account of wack sponsored by an agency of the United States Government. Neithez the United States Government nor the University of Califor nia nor any of their eoployees, makes any warranty, express or implied, ar assumes any legal tiability or responsibility for the arcuracy, completeness, or usefulness of any information, spparatus, product, of process disclosed, or represents that its use would not infringe privalely owned rights. Reterence herein to any specific comdiercial products, prosesg, or gervice by trade game, trademark, manulactutet, of otherwise, does nol necessarily cortstitute or imply its endorsement. tecommendalion, or favoring by the Liniled States Covernment of the University of California. Ihe views and opinions of authors empressed herein do nol necessarily state or reflect those of the Unjted States Government or the University of Caflornia, and shalf not be wed for advertising or product endorsement purposes.

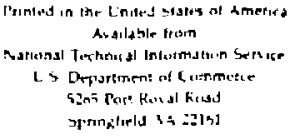

Price

Code

A01

Papercopy Prices

$\begin{array}{ll}\text { A02 } & 01-050 \\ \text { A03 } & 051-100 \\ \text { A04 } & 101-200 \\ \text { A05 } & 201-300 \\ \text { A06 } & 301-300 \\ \text { AD7 } & 401-500 \\ \text { A08 } & 501-600 \\ \text { A09 } & 601\end{array}$

Page

Range

Microfiche

Prepared by Nevada Nuclear Waste Storage lnvestigations (NNWSI) Project particlpants as part of the Civilian Radioactive Waste Management Program. The NNWS1 Profect is managed by the Waste Management Project Office of the U.S. Department of Energy. Nevada Operations Office. NNWSI Project work is sponsored by the Office of Geologic Repositories of the DOE Offlce of Civillan Radioactive Waste Management. 


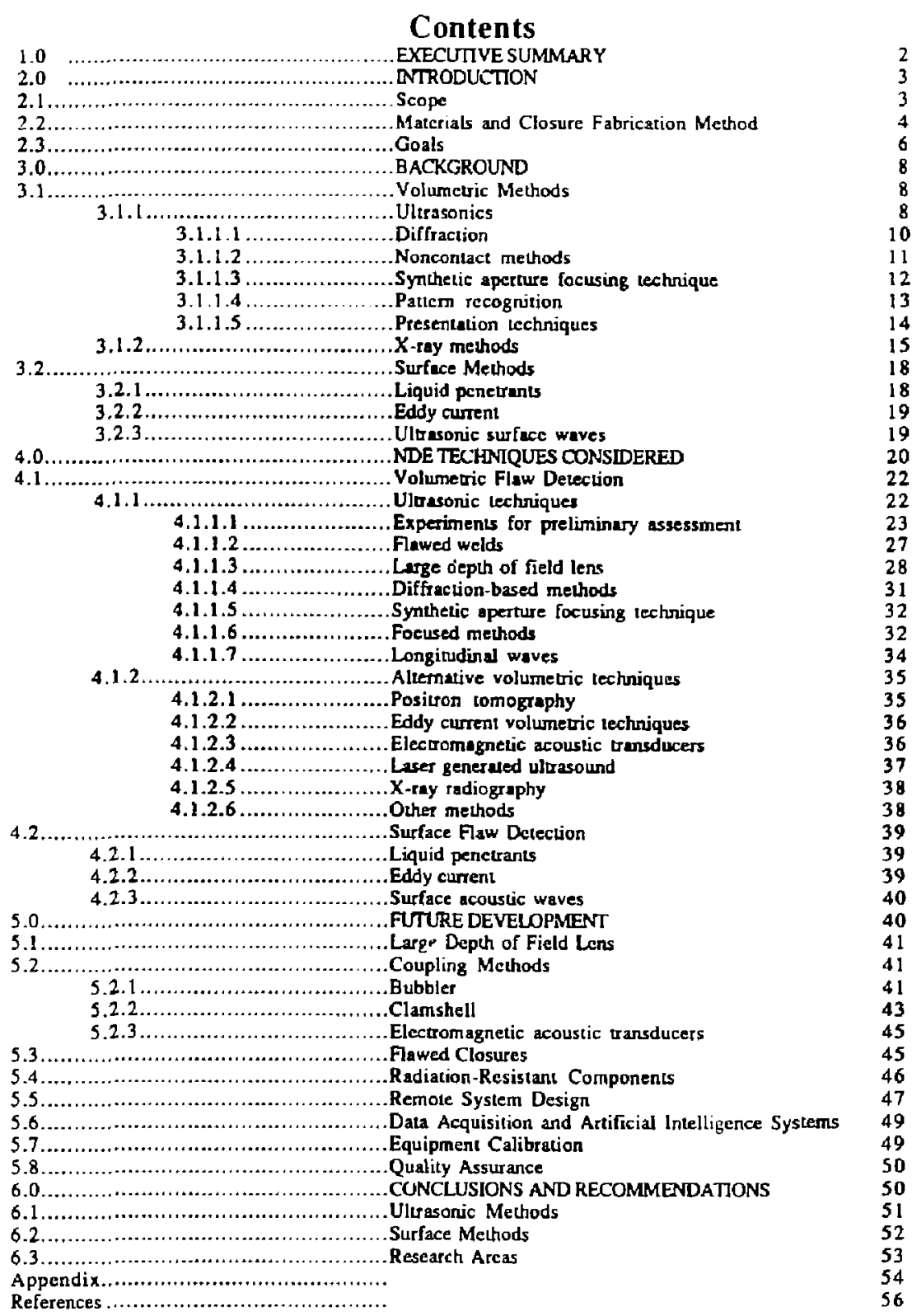

UCID- -21323

DE89 000236 


\begin{abstract}
Linder the direction of the Deparment of Energy's (DOE) Office of Civilian Radioactive Waste Management (OCRWMi) program. the Nevada Nuclear Waste Storage Investigations (NNWSI) project is evaluating a candidate repository site at Yucca Mountain, Nevada, for permanent disposal of highlevel nuciear waste. The Lawrence Livermore National Laboratory (LLNL), a participant in the NNWSI project, is developing waste package designs to meet the NRC requirements. One aspect of this waste package is the nondestructive testing of the final closure of the waste container.
\end{abstract}

The container closure weld can best be nondestructively examined (NDE) by a combination of ultrasonics and liquid penetrants. This combination can be applied remotely and can meet stringent quality control requirements common to nuclear applications. Further development in remote systems and inspection will be required to meet anticipated requirements for flaw detection reliability and sensitivity. New research is not required but might reduce cost or inspection time.

Ultrasonic and liquid penetrant methods can examine all closure methods currently being considered, which include fusion welding and inertial welding, among others. These NDE methods also have a history of application in high radiation environments and a well developed technology base for remote operation that can be used to reduce development and design costs.

Areas that require development include:

- Artificial flaw manufacturing 10 calibrate and qualify the NDE melhods.

- Transducer design and radiation resistance.

- Coupling ultrasonics into the container.

- Design of automated remote inspection system.

- Flaw detection sensitivity and sizing accuracy (signal processing).

Development required to meet program goals is described and recommendations are made for research that could reduce inspection cost and improve inspection performance.

\title{
DISCLAIMER
}

This report was prepared as an account of work sponsored by an agency of the United Siates Government. Neither the United States Government nor any agency thereof. nor any of thest employees, makes any warranty, express or implied, or assumes any legal liability or responssbulity for the accuracy, completencss, or usefulness of any information, appafalus, pruduct, or process disclesed. or represents thal its use would nut in rringe privately uwned rights. Refer. ence herein 10 any specific commercial product, process. or service by trade name. trademark. manufacturer, or otherwisc does not necessarily constitute or unply its endursement, eessmmendation. of favoring by the l!nited Siates fiovernment ut ally agency thertof The ateats and opinions of autiors expressed he-ein do not necessarily state of reflect those uf the United States Government or any ugency thereof. 


\subsection{EXECLTIVE SUMMARY}

Under the direction of the Department of Energy's (DOE) Office of Civilian Radioactive Waste Management (OCRWM) program, the Nevada Nuclear Waste Storage Investigations (NNWSI) project is evaluating a candidate repository site at Yucca Mountain, Nevada. [1] for permanent disposal of high-level nuclear waste. The Lawrence Livermore National Laboratory (L.LNL), a participant in the NNWSI project, is developing waste package designs to meet the NRC requirements.

The Nuclear Waste Policy Acr requires that the disposal container be retrievable for many decades and that containmem be substantially complete for many centuries. In this report, potential inspection techniques for the characterization of flaws in container closures are assessed (welding is one process under consideration but other processes are also under consideration). The closure is important because the majority of the residual stress will be borne by the container closure, which must remain free of objectionable flaws. The required long containment period (up to 1000 years.) might allow relatively small flaws to grow to an objectionable size. These factors require closure welds for radioactive disposal containers to be tested to detect and size flaws that are smaller than prevailing NDE practice and with statistical assurances that are higher than usually required of NDE methods. This repor describes methods to improve on prior practice and provide NDE performance capable of meeting the closure NDE requirements. This report fulfills the requirements of the H-20-3 Activity, Preliminary Ultrasonic Technique Evaluation.

The radioactivity level of the spent fuel will vary with the age of the waste (that is, years since removal from the light water reactor core), but the radioactivity will be strong enough to prevent application of conventional radiographic inspection of the closure weld. The use of unconventional rawiation methods, such as doping the weld metal with a positron emitter and performing positron tomography, are discussed but are considered not practical for this application. Ultrasonic methods are currently the primary volumetric inspection technique for this application because of demonstrated performance in the high radiation field and the ability to detect crack-like defects that are less than $5 \%$ of the container's wall thickness[2].

The use of dye penetrants for surface inspection is well established for remote use and is the primary method for outer surface defect detection. The selected volumetric method (ultrasonics) will be required to detect inner surface defects that will not be accessible to dye 
penetrants. Possible altemate methods for the outer surface inspection include eddy current and surface acoustic wave (SAW) methods.

\subsection{INTRODUCTION}

A schematic diagram of a disposal container illustrating features significant to closure NDE is shown in Fig. 1. The disposal containers are designed as thin-walled right circular cylinders with end closures and lifting fixtures on the end, Fig. 2 shows a proposed container design to be used wich consolidated spe ' $t$ fuel. The closure must be inspected remotely because of the high radioactivity of the high level waste: In addition, the inspection must meet a variety of unique requirements that are imposed because of metallurgical performance requirements dictated by the long containment period. Other factors that might affect the inspection system include the logistics of handling the container, the types of services available in the hot cell, and other operational constraints imposed by the repository design.

\subsection{Scope}

This work is a preliminary investigation of nondestructive examination (NDE) methods to be applied to the closure of the waste container. The scope of this activity is to identify potential inspection methods; to perform initial feasibility studies on these methods; and to define areas of furure investigation, testing, and basic research essential to meeting program goals. This information will be used in subsequent NDE activity [Container Closure Nondestructive Evaluation(NDE) Process Development ] to guide more detailed investigations of candidate NDE methods and their potential to achieve the goals (goals are described in Secrion 2.3). The container final closure NDE development activity will consist of a multi-year, multi-phase effort to assess NDE techniques identified by the prerequisite activity, Preliminary Ultrasonics Technique Evaluation; to recommend and demonstrate reference NDE techniques; and to design the full-scale system for the final NDE of disposal container closures at the repository. 


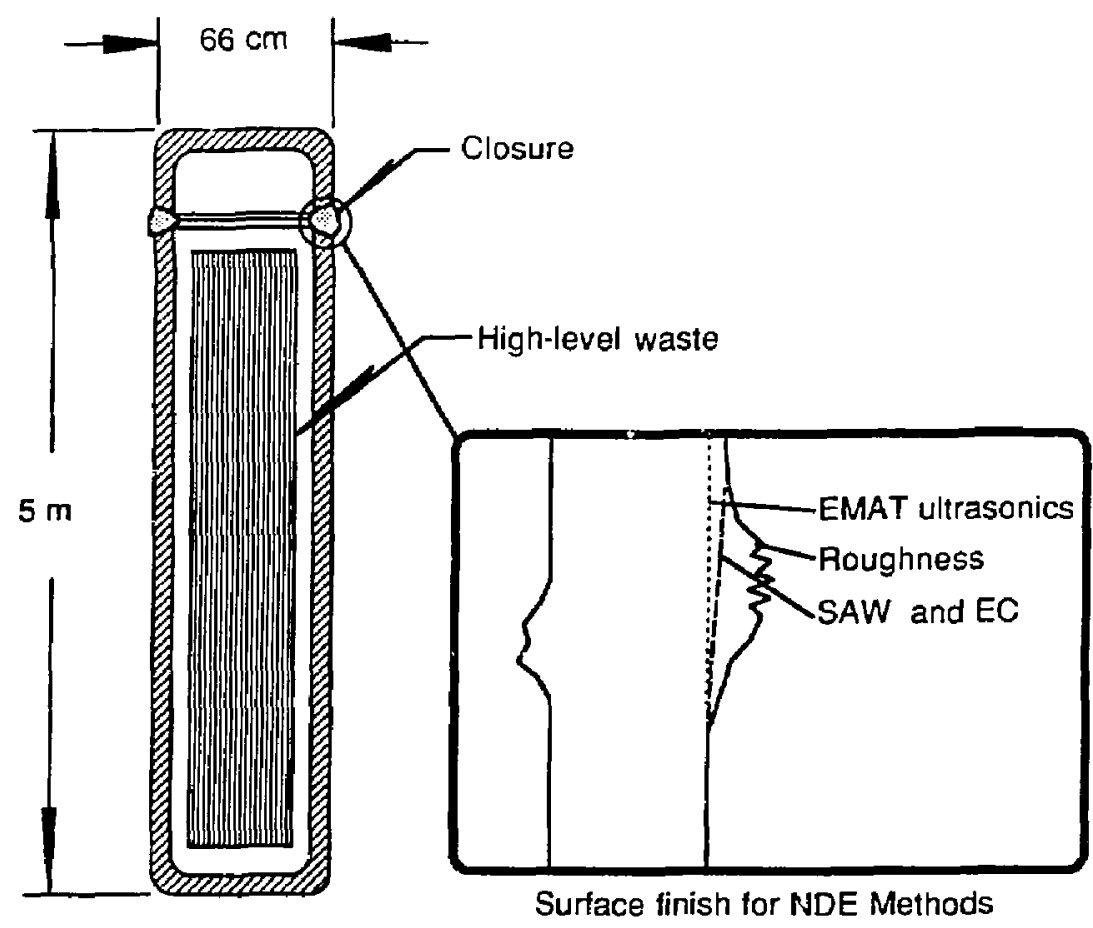

Figure 1. Container schematic illustrating features significant to NDE.

\subsection{Materials and Closure Fabrication Method}

The alloys under consideration for a disposal container are:

- AISI 304L - CDA 613

- AISI 316L - CDA 715

- Alloy 825 CDA 102

Although the container closure method has not been determined, one of the primary methods under consideration is welding. Weldments of the candidate alloys evidence anisotropic and inhomogeneous ultrasonic behavior, therefore, conventional weld 
inspections need to be improved (1) in detecting small defects in the weld region and (2) in reducing the probability of false detection of a flaw' .

Other closure methods might not lead to anisotropic or inhomogeneous ultrasonic properties. For example, inertial welds do not introduce remelting and would not have the preferred orientation that causes anisotropic properties. The container closure NDE activity will be pursued concurrently with three related activities dealing with fabrication and closure process development, remote system design and material selection. Information obtaired in one activity will be shared with the other activities.

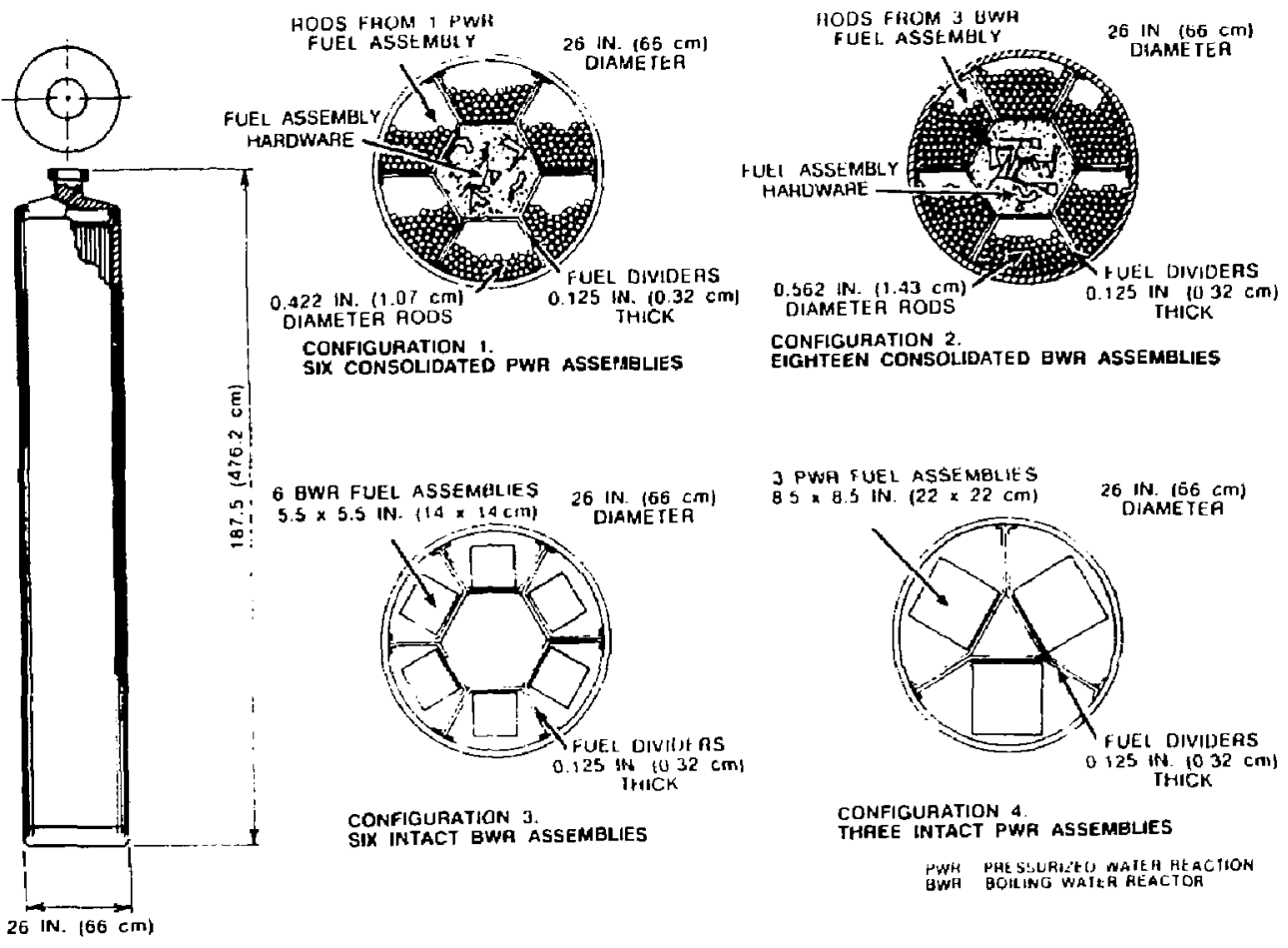

Figure 2. Consolidated spent fuel container conceptual design.

\footnotetext{
Copper based alloys and Alloy 825 are not as well understood as the AlSl 304 and 316 materials. A future addendum to this report will consider the potential pioblems associatcr with arisotropy in these materials.
} 


\subsection{Goals}

The purpose of NDE is to reject all closures that contain flaws larger than a critical size. The actual flaw size is important because it will determine the difficulty of developing a NDE method and because it will also influence the cost of closure.

For purposes of the following discussion, the actual critical flaw size will be referred to as $a$. The critical flaw size is defined as the maximum acceptable flaw size.

The assignment of a value to $a$ requires a complex interaction between ongoing container design/fabrication activities and metal barrier selection activities; as these activities evolve, information can be incorporated into defining a value of $a$.

Currently the constraints required for NDE process development are assumed to be as follows:

- The system must be a remote examination system that can compiete inspection without unreasonable service needs.

- The system must be sufficiently immune to radiation that it will be able to meet the performance goals without unreasonable maintenance requirements.

- The system must be capable of finding flaws of $a$ or larger with a probability of detection (POD) of approximately $90 \%$ and a false call rate of less than approximately $5 \%$.

- The probability of missing a flaw of $a$ or larger must not exceed approximately $10 \%$.

- Materials used during the inspection process must not compromise long-term performance of the container. The uirasonic couplant and the liquid penetrant must be totally removable or benign in the emplacement environment.

- The inspection method must size the flaw accurately and locate it relative to the container wall. The flaws locared near-surface are expected to be of more concerm than those located deeper within the container wall. The term near- 
surface flaw has not been defined but will be taken to be any flaw within a distance of $a$ from the surface.

- The flaw size must be accurately measured. The accuracy will depend both on $a$ and on the definition of near surface. The rejection criteria will depend on the value of $a$, the value of near surface, and the uncenainty in sizing. Therefore, a system that can accurately determine flaw size and location provides a significant advant:ge in contributing to a reliable and economic inspection.

The performance of modem NDE methods is now commonly rated in probabilities $[3,35]$ rather than the more traditional but vague minimum detectable flaw. In this case, the probabilities will be defined relative to $a$.

The first probability is for a Type I error. This error occurs when no flaw exists but one is incorrectly detected, which is frequenily referred to in ultrasonic parlance as a false call. This error is of particular concern in closure welding because the weld might not be repairable, in which case the contents would have to be removed from tine container and the entire closure process repeated. Clearly, this probability must be small since the cost of this error is high. Therefore, an estimated $5 \%$ probability has been set. Furure performance and materials considerations might change this value once the weld process is selected.

The second probability is for a Type II error. This error occurs when the flaw is not detected and is the converse of the probability of detection (POD). The NDE community usually defines the POD rather than the Type II error. The preliminary value for POD is currenty estimated at $90 \%$, which implies a $10 \%$ chance of missing a flaw greater than or equal to $a$. The value of $a$ is influenced by these probabilities because inspection performance is in terms of the value of $a$. That is, a smaller value for $a$ will require an inspection that is more difficult to perform. Conversely, the accuracy required in assessment of $a$ can influence the required POD since a higher POD can compensate for uncertainty in $a$ or in crack growth rates.

Another important process development constraint is flaw sizing accuracy. Flaw sizing is more difficult than flaw detection since the accuracy is only definable in terms of known flaws. One method to assure that a flaw is sized correctly is to require an operational test on a selection of known flawed and flaw-free components. This operational test (Qualification) must be performed on a regular basis by each crew of inspectors (with the actual equipment 
and software) in addition to periodic calior ttion. Actual periods for the Qualification will be determined in the Container Closure NDE Ptocess Development uctivity as the prototypical NDE system is developed.

The creation of closures with known flaws is currently being planned (Section 5.1 discusses flawed closures). This study of known flaws is important because ultrasonic methods, as most other methods, are sensicive to the nature and shape of the flaw.

\subsection{BACKGROUND}

To achieve the inspection goals described in Section 2.3, inspecrion methods that have been successful on face-centered cubic materials will be used in combination. Prior to discussing the specifics of the different inspection techniques relative to the closure requirements, the basic concept of each technique will be reviewed.

\subsection{Volumetric Methods}

Volumerric methods are used to detect and size defects that do not break the container surface or $r$ jat do not lend themself to surface-based inspection methods. Defects on the interior of the container as well as many weld defects fall into this category.

\subsubsection{Ultrasonics}

Ultrasonic waves (for NDE purposes, 1 to 20 megahertz frequencies or 5 to 0.1 millimeter wavelength) can propagate in solids with many different modes. Three modes are important in closure inspection: longitudinal, shear, and surface or Rayleigh waves. The velocity of each mode is unique, so each has a different wavelength and can be mode converted to other modes when reflected or refracted at a surface.

Longiudinal waves are conventional pressure waves (such as those we hear) and can exist in both fluids and solids. The particle displacement associated with the wave is in the same direction the wave travels. Shear waves have a particle displacement at right angles to the wave direction and can orly exist in solids. 


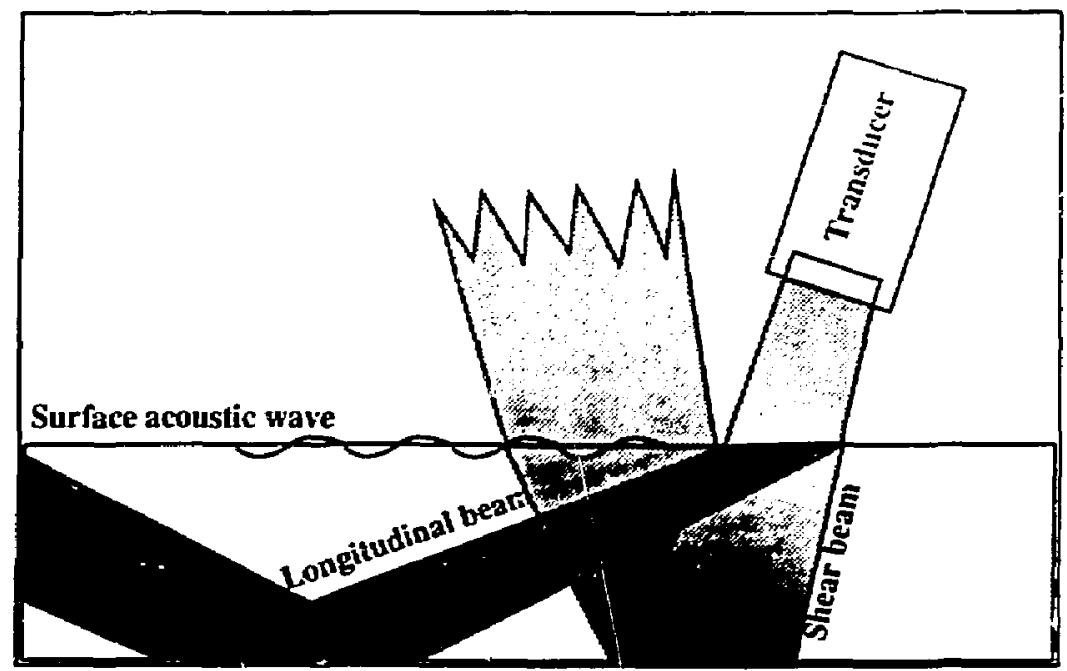

Figure 3. Ulurasonic waves can propagate in longitudinal, shear, and surface modes.

Figure 3 shows how ultrasonic waves can coexist and refract in solids. Refraction is controlled by Snell's law of optics, using acoustic speed instead of light speeds. Since shear speeds are always slower than longiudinal speeds, the angle at which the shear wave refracts is less than the angle at which the longitudinal wave refracts. The relationship of $\arcsin \left(N-\sin \left(\theta_{j}\right)\right.$ predicts the angle of refraction for both the shear an:t longitudinal waves, where $N$ is the ratio of sound speeds of the refracting materials and incident materials (and is Iypically smaller for shear waves than for longindinal waves) and $\theta$ is the angle of incidence. Clearly, as $N \cdot \sin (\theta)$ grows to be eqial to 1, a critical angle is reached with wo significant results: (1) the longitudinal wave is refracted to 90 degrees and only a shear wave exists and (2) a portion of the energy is convened into a surface acoustic wave (SAW). The result is called the first critical angle. Since the shear wave has a different $N$, it too can be refracted to 90 degrees from the vertical when this smaller value of $N \cdot \sin (\theta)$ becomes equal to 1 (the shear wave is slower than the longitudinal wave). This angle is called the second crivical angle. Beyond this second critical angle, only surface waves are generated.

The surface wave penetrates only a short distance into he inaterial, one or two wavelengths at most (approximately 3 millimeters for a 1 megahertz wave in steel). In air or a vacuum. the surface wave propagates with a lir loss rather than the familiar $1 / r^{2}$ loss $(r$ is the distance traveled by the wave). In water, however, the loss is very rapid since the 
surface wave mode converts back into a longitudinal wave and bleeds off into the liquid. The distance the SAW travels is only 10 to 20 wavelengths.

The reflection of sound from flaws and surfaces is complicated by (1) the incident wave being mode converted to one or more of the other two and (2) the wavelength being similar to the sizes of defects of interest. When the wavelength is one tenth or less of the flaw size. the flaw acts like a specular reflector and the angle of reflection equals the jncident angle. Specular reflection is unlikely for closure applications since it would require flaws about half way through the container thickness; hence the flaws will both reflect and diffract the ultrasound.

\subsubsection{Diffraction}

Smaller flaws tend to diffract (Fig. 4 illustrates diffraction) the sound at an included angle that is inversely proportional to flaw size. Diffraction is governed by the Lommel diffraction integral [4], which defines the complex relationship between the transducer and the flaw diameter. The included angle can be calculated by this integral but it does ignore the conversion of shear waves to longitudinal and vice-versa. The diffraction from the tips of cracks is also possible and can be calculated using funite difference or finite element methods. Diffraction is not intuitive and must be determined analytically and/or by experiment (we propose both approaches for container closure NDE). The diffraction from a simple shape, such as a disk, is only part of the scattered field. Additional scartering occures at the edge of the disk although weaker and this scattering is independant of the flaw size until it is very small relative to a wa:elength and it is in a different direction from the diffraction from the rest of the flaw. The reflected sound field of a flaw can therefore be complex and must be calculated in some detail to predict flaw detectability.

One difficulty presented by this phenomenon is that very small flaws can be detected independently of their orientation but very large flaws can be detected only through a narrow range of angles. One solution is to use multiple wavelengths and multiple ransducer angles to handle the directional dependence. 


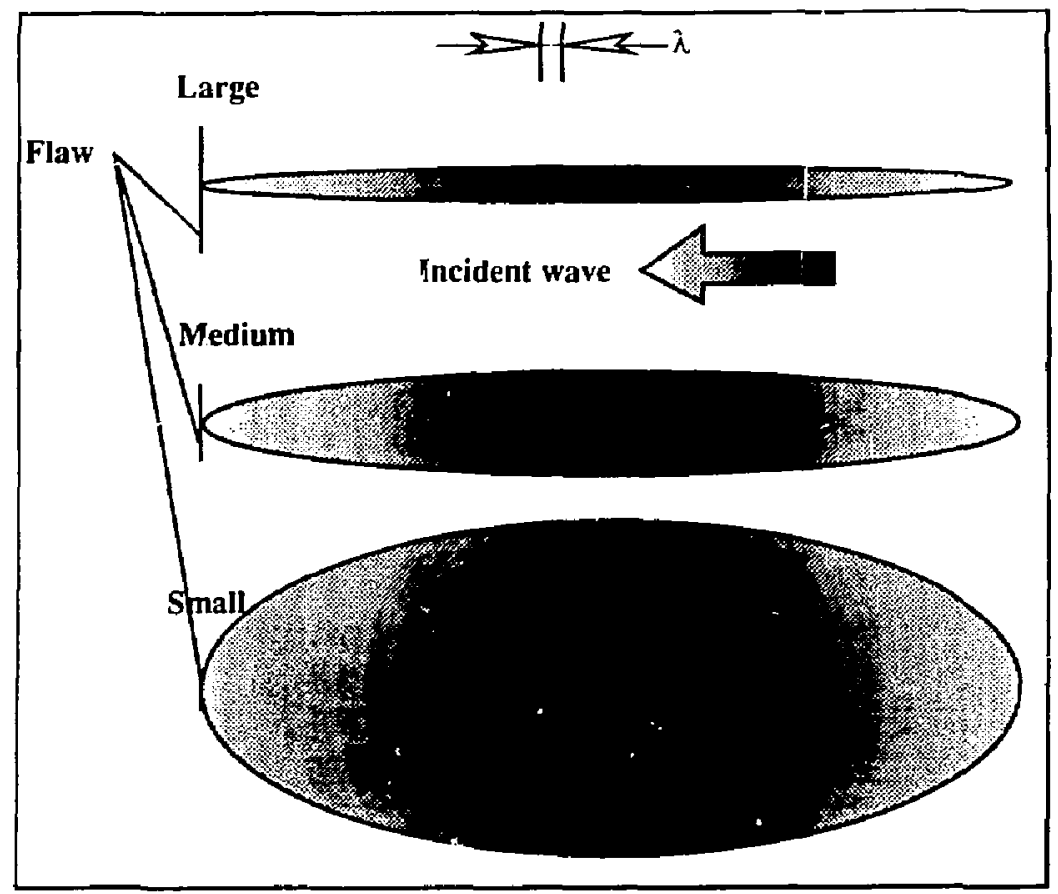

Figure 4. Ultrasonic diffraction from various size flaws; top, middle, and bottom are large, medium, and small diameter circular flaws, respectively. The gray areas are schematic representations of the sound intensity reflected from the flaws; the boundary of each gray area represents constant intensity.

\subsubsection{Noncontact methods}

A noncontacting method of generating and receiving ultrasound would be desirable for the remote NDE of waste containers since a couplant complicates the inspection. The generation and reception of sound by Electromagnetic Acoustic Transducers (EMAT) is one possibility. These devices are based on the principle that a current flowing in a magnetic field experiences a force $q v \times B$, where $q$ is the charge, $v$ is the velocity of the electrons, and $B$ is the magnetic induction. The implementation of an EMAT then requires a directcurrent magnetic field $(B)$ and a current flowing at the ultrasonic frequency (usually produced by eddy currents). Since a metal moving in a magnetic fjeld will also produce a signal, the retuming ultrasonic wave will produce a signal in the eddy current coils used to generate the wave. Hence in a magnetic field an eddy current coil can be made to generate 
and receive ultrasonic waves much like conventional transducers but with substantially liss efficiency.

Yet another noncontacting method of generation is a pulsed laser which will heat the surtace of an absorbing material and create a themal wave. This local heated zone converts to conventional sound waves (both longitudinal and shear). The amount of sound generated is proportional to the coefficient of thermal expansion (CTE), the specific heat at constant volume, and the laser energy. Most metals have a high CTE so that laser generation of sound is telatively efficient. Since energy input must be well below that which would melt the material being inspected, there is a sharp limit on the amount of sound that can be generated. This limit is comparable to what piezoelectric ransducers can generate in materials.

The reception of laser-generated sound can also be accomplished optically using an interferometer. This method generally requires a reflecrive surface that is smooth over a short (approximately 100 micron) scale. Because the transmission with a piezoelectric also requires a smooth, flat surface that is several millimeters, this is not a problem. The generation of sound (at a point) and receiving of sound (at a point) using the laser has been demonstrated by combining the optical interferometer with a pulsed laser. This is roughly comparable to a piezoelectric system but would require development to be capable of competing with the ultrasonic techniques described in Section 4.1.1.3.

\subsubsection{Synthetic aperture focusing technique}

Synthetic Aperture Focusing Technique (SAFT) $[21,32,33-35,38-43]$ was developed for nuclear reactor pressure vessel examination and for austenitic nuclear piping weld inspection. By using this ultrasonic method, one can obtain a focused ultrasonic examination through long path lengths in metals thit cannot otherwise be obtained with available transducers. As the thickness of the metal becomes smaller, the advantages of this method decrease (see Fig. 5) in comparison to conventional focused transducers. The advantages of SAFT are greatest for thickness greater than $25 \mathrm{~mm}$.

This method is based on the principle of superposition, which essentially says an ultrasonic wave can be made by adding up small waves (point sources). The point sources are created by using transducers that are focused at the surface of the closure, as shown in Fig. 5. As the transducer or transducers are moved along the pan, data is obtained for the 
signals at each locaticn. If each signal is shifted in time the correct amount, the signals will add together as though a synthetic aperture and focus had been used. The size of the aperture is controlled by the number of point sources, that is, the number of samples taken multiplied by the spacing between them. The focus depth is determined by the time shift for each point source. Because this time shift can be repeated for many different sets of time shifts, the focus depth can be very large. The aperture is only controlled by inow far the beam of sound can spread in the material, which is limited by mode conversion to approximately 40-60 degrees. The wave mode converts to shear waves when the first critical angle is reached (Fig. 3), and these waves cannot be used in the synthetic focus because they have a different time shift.
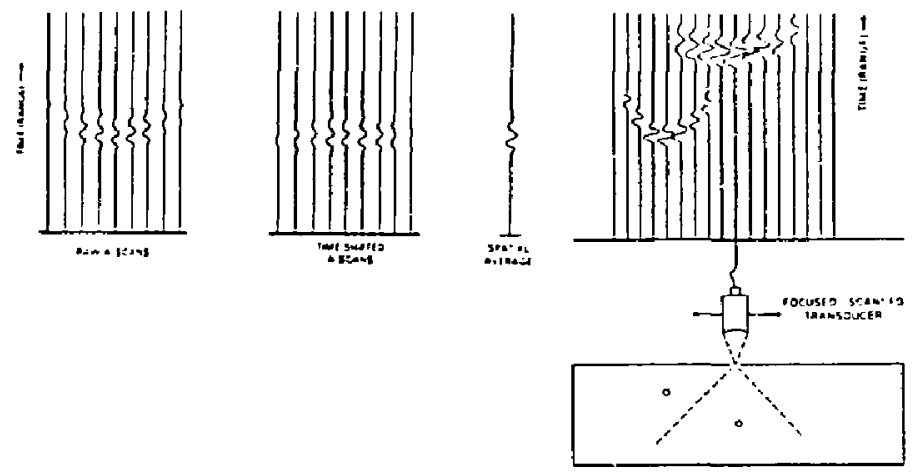

Figure 5. Synthetic focusing achieves focusing by time shifting the received signals (right side) obtained with an unfocused beam and summing them to obtain a spatial average. This is done for every signal in the synthetic aperture and at every depth of focus.

\subsubsection{Pattern recognition}

Pattern recognition techniques have been shown to be effective in providing better flaw detection and sizing capabilities. These techniques use features of the ultrasonic signals to enhance the information contained in the signals. Typically the approach treats factors such as the signal rise time, power, time domain behavior of the signal, and similar factors as 
data to be statistically analyzed. The approach includes uncerainty in we relationships among these variables and the factors to be measused, such as flaw size.

The rise time from a crack might be less than 20 nanoseconds while the power in the reflected 2-3 megahertz band is usually twice as great as that in the 1-2 megahenz band if the signal is from a crack. There is inherent uncerainty in each factor taken alone, but by combining these parameters in the correct way, the overall uncertainty would be reduced. In acrual practice, dozens of factors are used to improve the ability to make a pattern emerge from the data (typically by multi-variate regression). Thus, a better measure of defect size or more reliable defect detection can result [27].

\subsubsection{Presentation techniques}

The presentation of ultrasonic data is complex and three methods are commonly employed to represent the data in a more meaningful way. The first method is called A-scan and represents the amplitude of the ultrasonic signal as a function of time. Knowing the geometry and the speed of sound, we can convert the A-scar into space coordinates (millimeters or inches). However, refraction of the waves causes the space coordinates to be at an angle and internal reflections in the part further complicate the A-scan interpretation. The sound generally travels in a V-shaped path so that the simple linear model of the A-scan does not accurately show the true location of a signal. The sound can also travel by other paths and arrive at the same time, making the interpretation more difficult. Ultrasonic tests are carefully designed to avoid the interpretational problems associated with the data presentation, and other presentation methods have evolved tn mal interpetntigs easict.

The second method is called B-scan. This presentation is a graphical summary oi multiple A-scans taken at different locations (essentially a 3-D display). The third dimension is the amplitude of the ultrasonis signal. This representation is an improvement over the A-scan because the relationship between the reflections can more readily be interpreted as the transducer is moved. The display of the B-scan does not represent the actual part or flaw shape because of the distortion caused by refraction and reflection of the sound beam.

The third method, called $\mathrm{C}$-scan, is obtained by taking only the maximum signal during a specific time period of the A-scan. This process is analogous to searching the A-scan from it start to a stop time and calculating the maximum ultrasonic amplitude. This amplitude is then plotted in color or shades of gray on a map that relates the value taken to the position of the 
uansducer when that A-scan was taken. The total effect is a map of the signals during a specified time that look like a plan view of the part. The times are chosen so that this map can be related to the flaw depth or severity of flaw at the depth range enresponding to the start and stop times selected. Several such maps can be made simultaneously at different times or depths in the material. C-scan is easy to interpret but is known to produce inaccurate flaw sizes when used by itself. The information contained in the A-scan is needed to perform more sophisticated flaw sizing anc signal processing tasks.

\subsubsection{X-ray methods}

$\mathrm{X}$-rays penetrate solids and are absorbed by a variety of complex processes that relate to material density and thickness. The absorption can be represented by

$$
I=I^{\prime} e \cdot \mu x
$$

where $I$ is the intensity of transmitted $x$-rays, $I$ is the incident intensity of the source of $x$ rays, $\mu$ is the effective absorption coefficient, and $x$ is the thickness of the material. The absorption coefficient is a complex function of the x-ray energy and the material density and composition but is roughly proportional to density if the other parameters are held constant. Thus, the fundamental concept of radiation-based methods is to record via film or x-ray sensitive detectors the intensity of the transmitted radiation. This provides an image of the density times thickness (DXT) of the sample. In film radiography a full planar view of the object is recorded, whereas gaging methods employ accurate point-by-point evaluation of DXT. Since most defects are different in density from the parent material, $\mathbf{x}$-ray methods image flaws so they can be interpreted by the human eye.

The formation of images of the waste container closure is complicated by the radioactivity of spent fuel. Typical estimated values at the closure surface due to the spent fuel range from 1000 to $100 \mathrm{RADs} /$ minute. This is the same order of magnitude a typical $x$-ray source will produce. The formation of an image is made very difficult by this background radiation level, which will fog the film faster than the $x$-ray source will.

Several possible solutions exist. The best is to use a gaging method with double collimation, i. e., both source and detector collimation (Fig. 6). Gaging is better able to deal with the high leveis of background radiation for tho reasons: (1) the double collimation allows direcrional detection that will exclude much of the background radiation and (2) the 
radiation source and detector are matched so that only radiation from the volume seen by both collimators is detected.

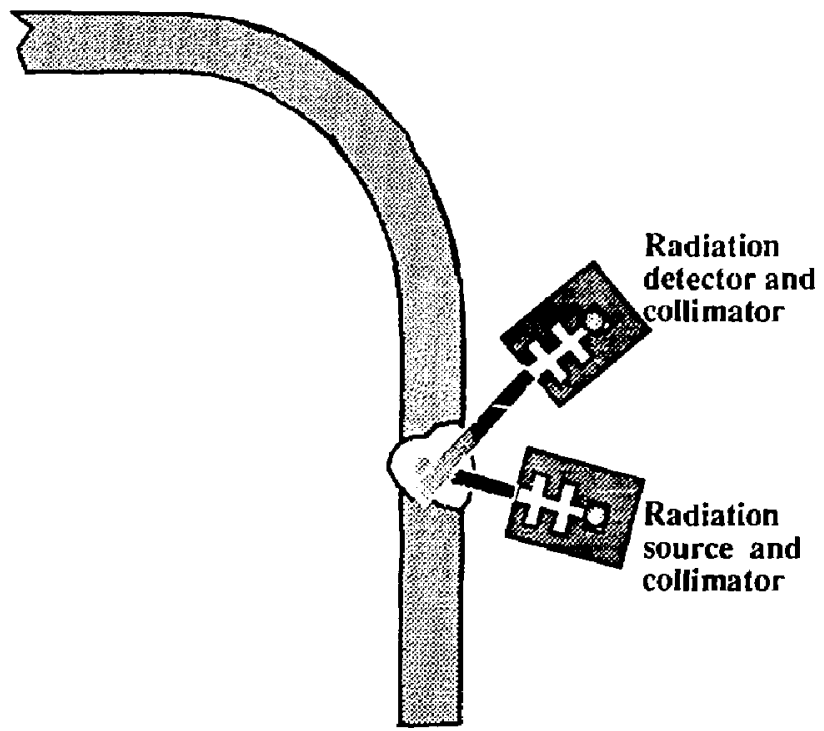

Figure 6. X-ray gaging might be applied. The source collimator and detector collimator define two beams that intersect in only a small volume in the container and exclude most radiation coming from other parts of the waste package.

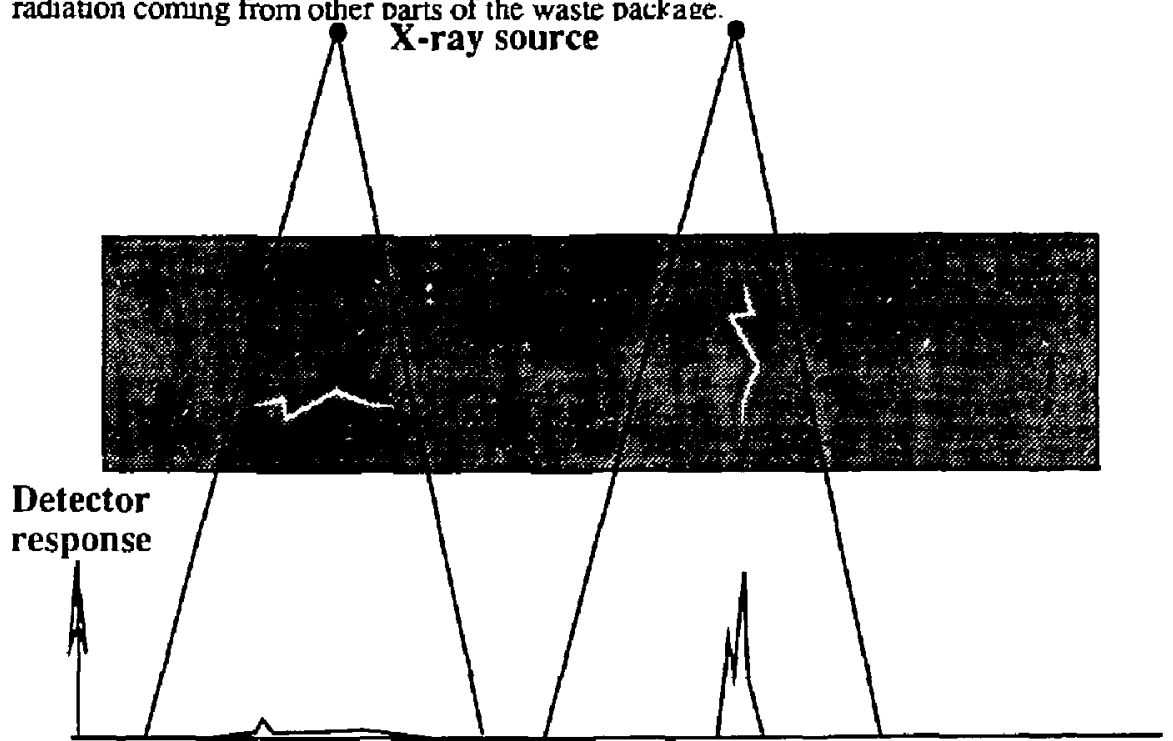

Figure 7. X-ray gaging is not sensitive to cracks because the crack must be aligned with the $x$-ray beam (on the right) for the crack opening to be visible. In principle, a crack with a very small opening cannot be detected. 
Gaging is generally much slower than other $x$-ray methods because it gathers data one point at a time. This can be improved, however, by the use of multiple sources and detectors. Detection levels for most flaws using the gaging method is as good as detection levels using conventional $x$-ray methods. Unfortunately, the detection of small crack-Jike defects is not as good as when using ultrasonics (Fig. 7). This insensitivity to cracks makes $x$-ray methods less attractive than ultrasonics for the closure examination.

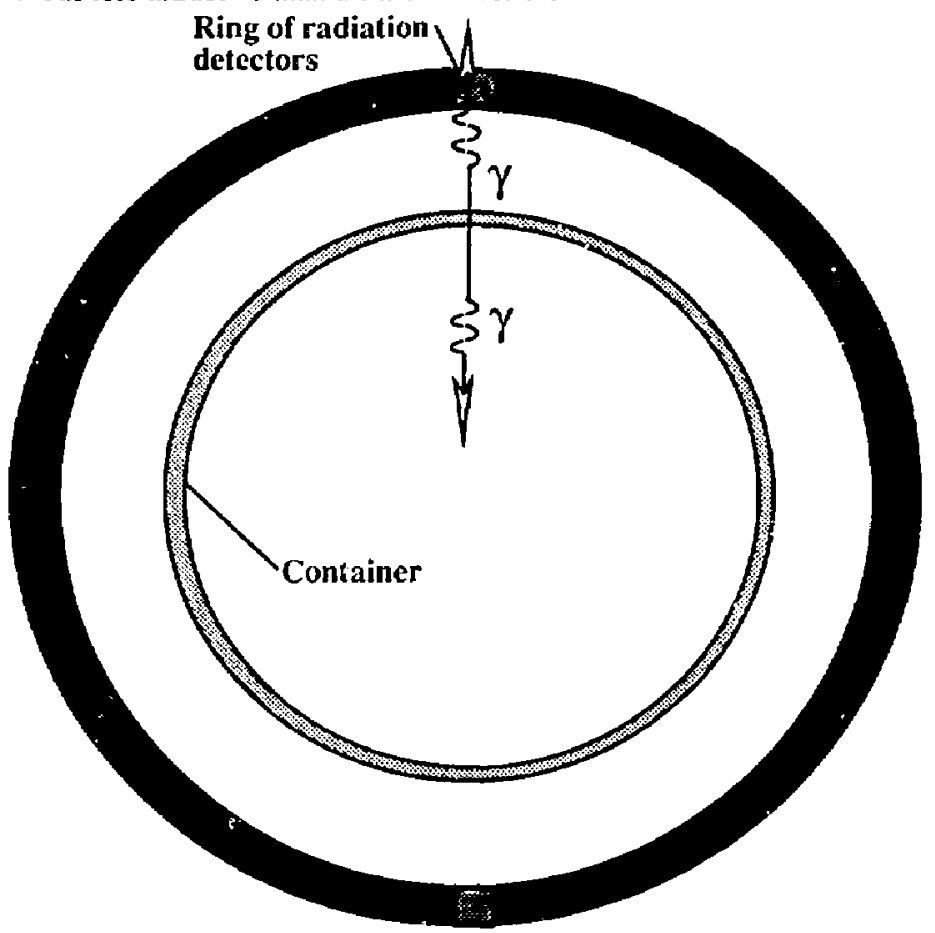

Figure 8. Positron tomography, shown in plan view, uses gamma $(\gamma)$ rays emitted in opposite directions to locate the position of the positron emitter in the closure.

Another potential x-ray method is positron tomography. Positron tomography requires that the materials to be examined be doped with a positron emitter. These emitters need only be provided in trace amounts but will make the container radioactive. The method uses the $\mathrm{x}$-rays emitted by positron-electron annihilation to fonm tomographic images (Fig. 8). Two $x$-rays are emitted in opposite directions ai 511 kiloelectron volts (this energy is the rest 
mass of an electron and is independent of which dopant is used) so that the detection of both direction and energy can be used to discriminate against the background radiation. This method can detect features approximately 1 millimeter long in biological applications, and improvements could be made in the inspection of metals that could potentially make the method as good as $x$-ray gaging. Improvements include use of higher levels of radioisotope combined with smaller diameter collimators.

\subsection{Surface Methods}

\subsubsection{Liquid penetrants}

When the surface is accessible and the flaw breaks the surface, then a surface method can be used. Most methods have a means to increase the visible width of the flaw so that the flaw can be seen. The most popular method is liquid dye penetrant, which uses a dye that penetrates surface-breaking flaws. After applying the penetrant, the surface penetrant is removed and a developer is applied that draws the dye out of the defect so that it can be seen. Any material that will make the flaw visible can be used, and a vast array of existing materials (from food coloring to radioactive gas) have been empioyed. Currently hundreds of materials are available for a wide variety of materials and applications.

In spite of its apparent simplicity, liquid penetrant testing has been well characterized experimentally and theoretically and has become increasingly sophisticated. An extensive data base on material compatibility shows penetrant materials to be compatible with most steels over engineering time periods [5]. Unfortunately no data base exists for time periods greater than a few decades; therefore, leaving these materials on the container will not be permissible.

Removal of liquid penetrants is a well-developed science that provides a relatively high assurance that no residues remain. Hot cell and remote use has been resuricted to experimental and special-purpose applications for nuclear reactors. Removal of liquid penetrants has been accepted for nuclear reactor inspection applications, but the periods between reinspection does not exceed 20 years under currem practices. 


\subsubsection{Eddy current}

Another surface method that has been shown to be very effective at finding surface and near-surface flaws in conductive metals is eddy current. For some aerospace applications, eddy current has replaced liquid penetrants because of its high speed and ability to penetrate a short distance into the surface.

The principle of eddy current testing is the interruption of eddy currents, generated in the material by a coil when a flaw is present. The eddy currents penetrate a distance into the material controlled by the test frequency [6]. The distance is inversely proportional to frequency.

$$
\beta=((\operatorname{cog} \mu) / 2)^{I / 2}
$$

where $\beta$ is the distance the current falls to $/ / e$ ( $e$ is the base of natural logs) of its original value, $\omega$ is the angular frequency, $g$ is the conductivity, and $\mu$ is the permeability. The ability to see small flaws is a:so inversely proportional to frequency ( $\omega=l / f$ ) so that the depth of penetration must be weighed against the need for sensitivity. Also, practical considerations limit the depth of penetration to approximately 6 millimeters in most conductive materials.

Eddy current performance has been demonstrated in conducrive and ferromagnetic materials to be equal to (and in some cases exceed) the performance of liquid penetrants [7]. Eddy current requires no couplant and, with proper coil materials, is virtually immune to radiation. The disadvantages are that it cannot easily handle rough surfaces such as welded materials, it requires extensive development (to handle the variation in material conductivity and/or magnetic properties) for each material, it cannot easily hardle mixed phase materials such as retained ferrite in austenitic metals, and it is slower than liquid penetrants for the waste closure. Eddy current is also a volumetric method when the frequency is lowered to allow penetration of the material. The detectable flaw size increases under this condition.

\subsubsection{Ultrasonic surface waves}

As mentioned earlier, the surface wave travels only on the surface, but the wavelength can be chosen so that its penetration can be selected to be anything from 3 millimeter to 3 microns. The propagation of the surface wave is similar to the other modes of propagation in that the surface wave will reflect from a flaw in its path. This fact has been used to inspect 
surfaces by generating a wave and looking for reflections from flaws. When no liquid is on the surface, the surface wave can travel large distances with little attenuation, which can be used to inspect very large surfaces quickly.

Unforunately, surface roughness can scatter the wave. Also, many ultrasonic tests are conducted in water, which contributes to the attenuation. A hybrid water surface wave test has been developed that requires the surface wave to propagate only a few wavelengths to detect flaws. This method has been used to inspect reactor piping and welds in light water reactors and might be applicable to closure weld inspection [8].

The principle is simple in that a surface wave reradiates into the water at a unique angle determined by the water sound speed and surface wave speed. This angle is $30-40$ degrees in the same direction the surface wave travels. If the surface wave is reflected from a flaw, then the resulting reradiation is back in the direction from which the original wave came and can be received by the transmitting transducer.

Since the transducer must be scanned over the entire surface, this method is the slowest of the three surface methods. Since the surface wave is reflected from rough surfaces, this method is also difficult to apply to welded surfaces that scatter and reflect the waves and confuse interpretation. Claims of performance similar to that of dye penetrants have been made [10].

\subsection{NDE TECHNIQUES CONSIDERED}

The various methods considered for volumetric examination are compared in Table 1, and the methods considered for surface examination are compared in Table 2. Some methods have been eliminated because they will require significant research, and others have been eliminated because they do not meet the anticipated performance requirements.

\section{Table 1. Comparison of Volumeiric Methods}

\begin{tabular}{|c|c|c|c|c|}
\hline Method & Rank & Status & $\begin{array}{l}\text { Chance } \\
\text { for Improvement }\end{array}$ & Best Sensi \\
\hline Ultrasonic & 1 & Mature technology & Good & $1 \%$ \\
\hline Eddy current & 2 & Mature technology & Poor & $\mathrm{J} 0 \%$ \\
\hline EMAT ultrasonic & 3 & Development req. & Poor & $5-10 \%$ \\
\hline Positron tomography & 4 & Innovation req. & Reinow & $10-20 \%$ \\
\hline X-ray radiography & 5 & Mature technology & Very remote & $50 \%$ \\
\hline Laser ulerasound & 6 & Innovation reg. & Very remole & Unknown \\
\hline
\end{tabular}




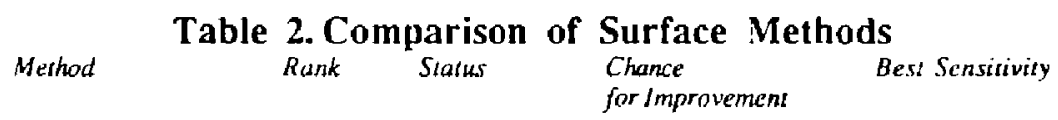

\begin{tabular}{lllll}
\hline Liquid dyc penctrant & I & Mature technology & Poor & $0.1 \%$ \\
Eddy curent & 2 & Requires crown removal & Fair & $0.1 \%$ \\
Ulurasonic surf wave & 3 & Requires crown removal & Fair & $0.1 \%$ \\
\hline
\end{tabular}

The choice of a method relies on judgment based on the demonstrated performance of the method described in the literature. The judgment criteria include the following:

- Ability to detect crack-like flaws between 1 and $10 \%$ of container wall thickness.

- Application in a remote environment.

- Radiation resistance.

- Ability to deal with a rough surface on both the outside and inside of the container.

- Potential of a reliable prototypical system, capable of anticipated production, with minimal operator judgment required.

Methods that were eliminated by these criteria include:

- Laser ultrasound because it is not demonstrated in a high radiation field and is potentially vulnerable to radiation darkening of optical components.

- X-ray radiography and gaging because of the poor crack detection ability and the interference from the high background radiation.

- Positron tomography because of the difficulties in handling the radioactive materials and the poor crack detection ability.

- Eddy current volumetric methods because of the poor crack detection ability and the difficulty in handling weld surfaces. 
- EMAT methods have potential but require better efficiency and higher frequency capabilities than demonstrated by cursent systems on conductive melals.

Ferromagnetic materials are potentially more efficient and would improve the chances of using this method for closure NDE.

\subsection{Volumetric Flaw Detection}

The volumetric method must be able to detect a variety of flaws and to characterize their dimensions with sufficient accuracy to meet the goals described in Section 2.3. The primary laws of concem are those near a surface and those that are crack like.

\subsubsection{Ultrasonic techniques}

Ultrasonic methods are the most promising volumetric method because of a demonstrated ability to detect small crack-like defects in austenitic weld metals. Referring to Table 1, we see that ultrasonics is the mosi sensitive (1\%) method. The method is also the only crack detection method that has a demonstrated crack sizing capability in welds [9].

Ultrasonic experience exists to examine austenitic welded pipe remotely at temperatures to $200 \mathrm{C}$. One area identified as needing additional work is that of dealing with the weld metal inhomogeniety and anisotropy. Some system design issues were identified for this technology but ultrasonics is currently the only demonstrated remote volumetric examination method. This method was demonstrated on Type 316 stainless steel welds but extension to other alloys seems to be straightforward [10]. The demonstrated technology was tested under more severe robotic conditions (more complex and at a greater distance) and at a higher temperature than required for hot cell use.

A large body of work in the ultrasonic inspection of austenitic piping contributes to :he belief that this technology holds promise for closure examination but difficulties have been encountered with some alloys and weld methods. Ultrasonic examination of some weld methods may be more difficult than expected for any of the candidate allo's. Ultrasonic properties of copper alloy based welds are less well known [12] than the cther alloys, bence they are more likely to have difficulties. Existing information seems to indicate that cast copper alloys will be similar to cast ausicnitics which suggests their welds will also be 
similar, therefore, the ultrasonic methods developed for austenitics may be applicable to copper alloys.

Clirasonic methods are well established for weld inspection remotely and in high radiation fields [11,10.26-29] in austenitic materials. The flexibility and versatility of ultasonic techniques is well known and allows this method to accommodate a variety of closure methods and materials without catastrophic difficulties. The purpose here is to show the number of known methods that improve the ultrasonic testing of welded austenitics, which help demonstrate its versatility. These enhancement methods can be combined to achieve a grealer performance than each can achieve by itself.

The use of focused transducers at multiple refracted angles and frequencies can be combined with tandem two-ransducer methods. The diffraction in the weld region will be studied to infer its properties using the 14-axis two-transducer Ultrasonic Test Bed. The use of Synthetic Aperture Focusing Technique and Pattern Recognition methods are also being pursued because of their success on anisotropic/inhomogeneous materials. Addinional improvements are sought to understand more clearly the stariscical properies of the calibration process and to optimize the statistical control of the NDE test.

\subsubsection{Experiments for preliminary assessment}

The following experiments, which were conducted to assess potential performance of ultrasonic inspection using a remote system, serve as standards of the present technology. Type 304 siainless steel welds and Incoloy 825 base material were inspected to assess the performance of ultrasonic methods in these materials. Copper we ld ultrasonic properties kere not measured but will be done latter.

Artificial defects of $1,2,4,6,8$, and $10 \%$ of the nominal container wall were fabricated on a section of pipe. These notches were used to calibrate both $\mathrm{C}$-scan and B-scan data on weld specimens. Although the welds are not protorypical, they are similar in materials and geometries to some candidate materials. These similar specimens are believed to reasonably model problems likely to be encountered in welded closure of all the candidate container materials. Other joining methods are under consideration: it is not known if these specimens are a good model for these other closure methods. 


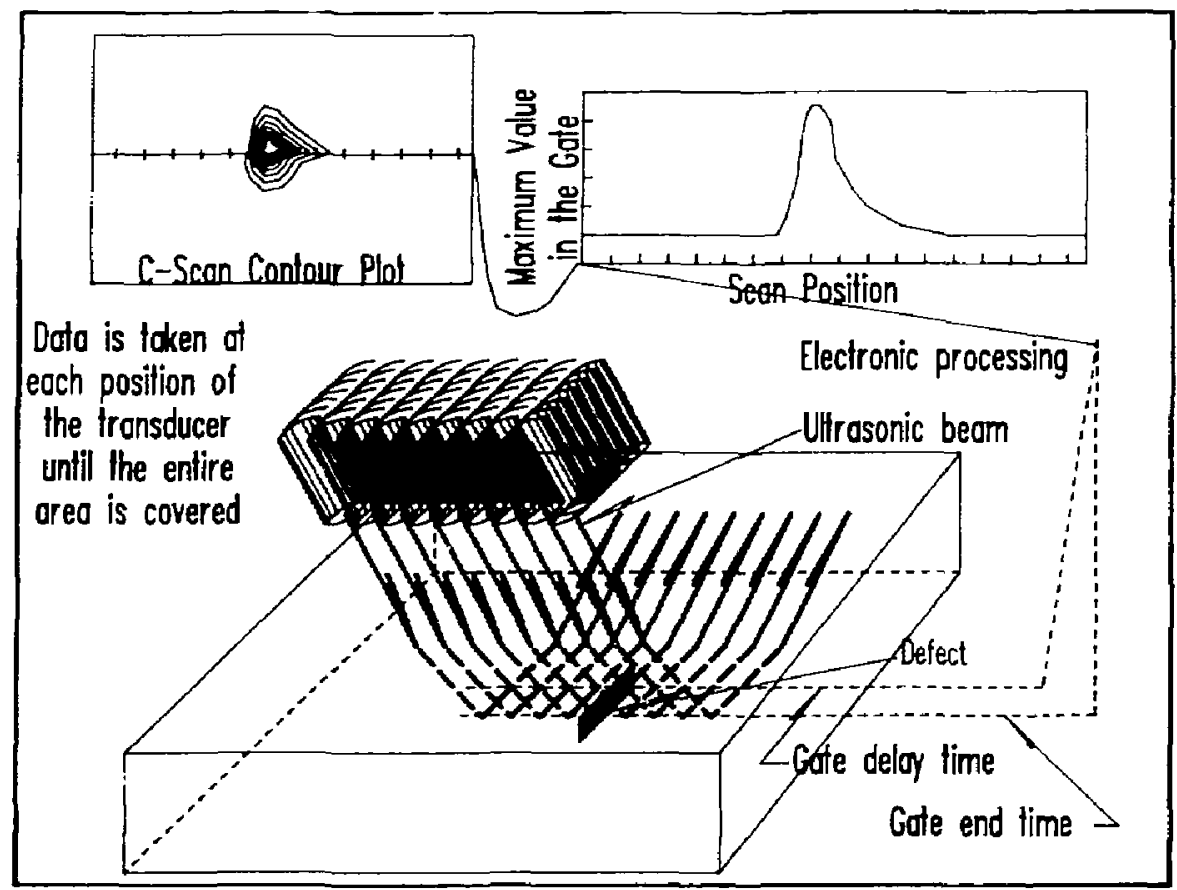

Figure 9. Inspection of sample defects using the C-scan method.

A C-scan is obtained by electronic gating of the ultrasonic time signal (Fig. 9). The voltage (ultrasonic amplitude) vs. time trace is called an A-scan. Because the time signal gate corresponds to a specific distance traveled in the material, only signals that occur at that distance are included in the $\mathrm{C}$-scan. The $\mathrm{C}$-scan data can be represented by a spatial map that can be viewed as a plan view of one depth of ultrasonic indications in the material. There is no limit to the number of such views except for the practical limit of time resolution of the ultrasonic system employed. Typically, two to three such maps are necessary to provide complete coverage of a weld. One disadvantage of this method is that the data cannot be signal presessed later. Samr' $\cdots$ of a weld C-scan presentation are shown in Fig. 10.

The value of the ultrasonic signal is ideally proportional to the flaw severity or depth but in practice this approach is only approximately correct and additional information is needed to measure flaw depth accurately. The principal advantage of the C-scan method of processing the data is that it is easily understandable and can be done with a modest amount of computer storage for the data. 


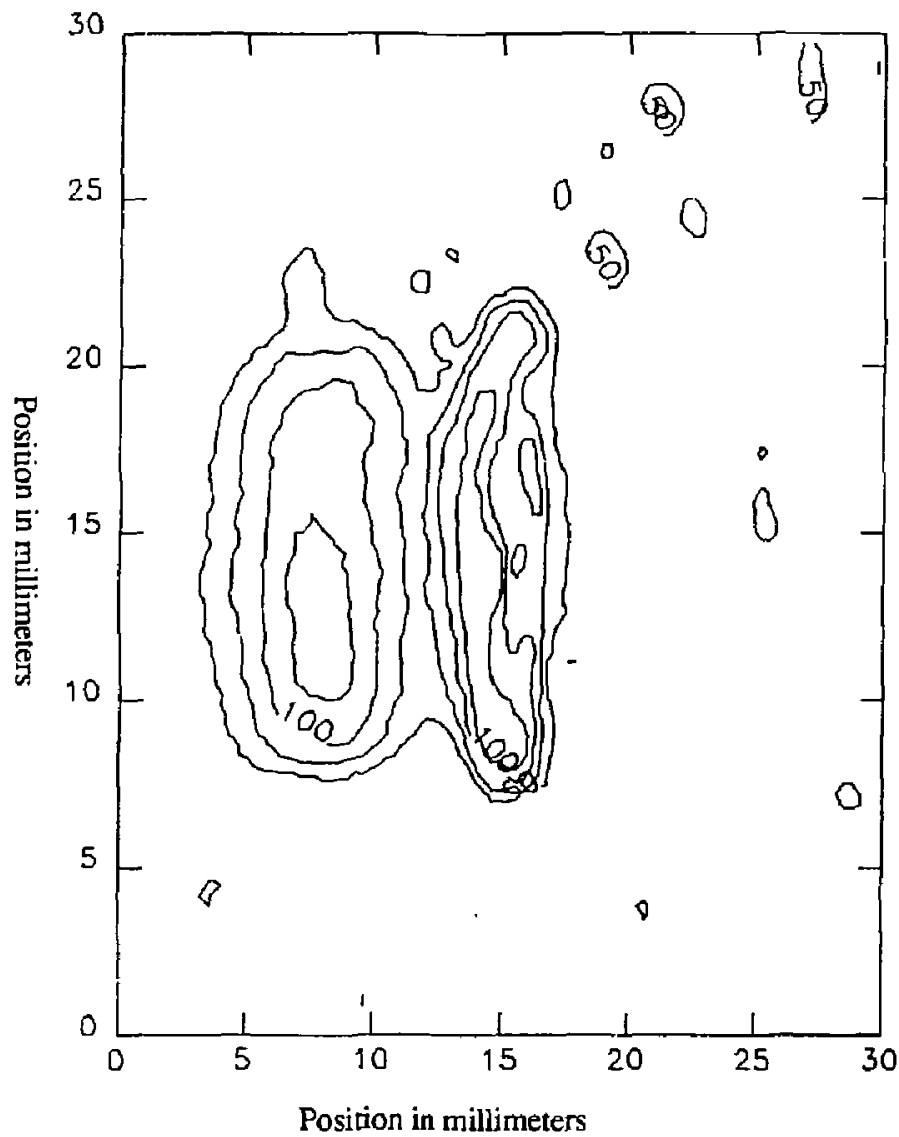

Figure 10. Sample C-scan of weld. The weld is on the right side ( 25 millimeter), and defects have been created on the left side of the weld ( $5 \%$ depth), one on the top surface (left) and one on the bottom surface (right). The contour plot shown here is one possible way of displaying the data; others include color and gray scale images.

The B-scan method is illustrated in Fig. 11. The B-scan method stores the entire time series or A-scan information at each sample point of the uitrasonic transducer. This method uses larger amounts of data storage because up to several hundred samples will be required at each transducer location. The disadvantage of the large data storage requirement is offset by the ability to perform sophisticated signal processing methods (including those not yet developed) and by the ability to provide complex time of flight information, sometimes called echodynamics; these advantages are important in flaw sizing [13]. This method is now used for a variety of commercial vendor inservice inspection systems.

One significant disadvantage of the B-scan method is that it can only be interpreted by an expert and is largely incomprehensible without extensive explanation. One method of solving this has been implemented for SAFT by presenting the data in a plan view or a 
cross-sectional format that presents a less distorted representation of the data. A typical weld B-scan is shown in Fig. 12.

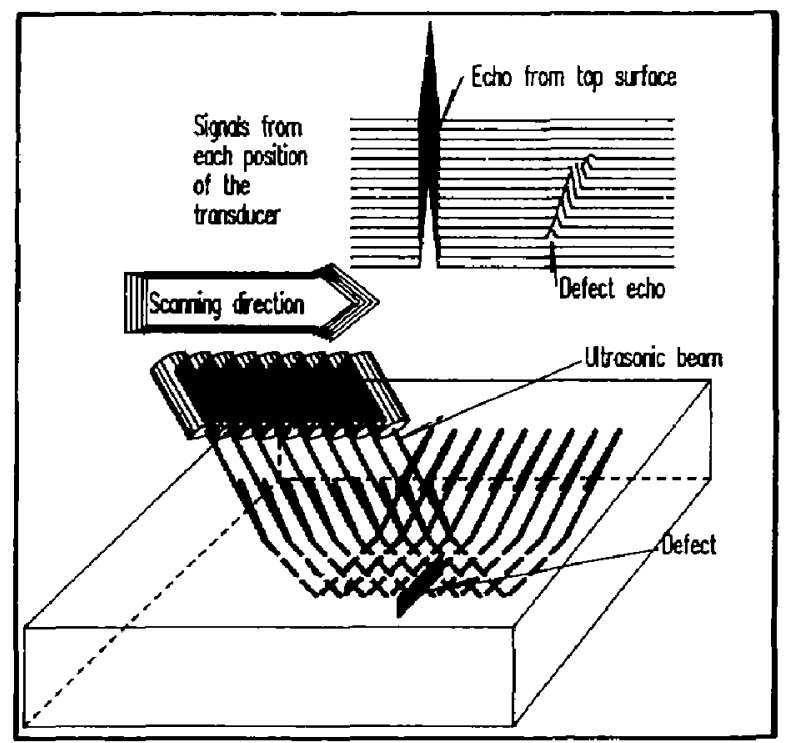

Figure 11. B-scan method iliustrating echo dynamics.

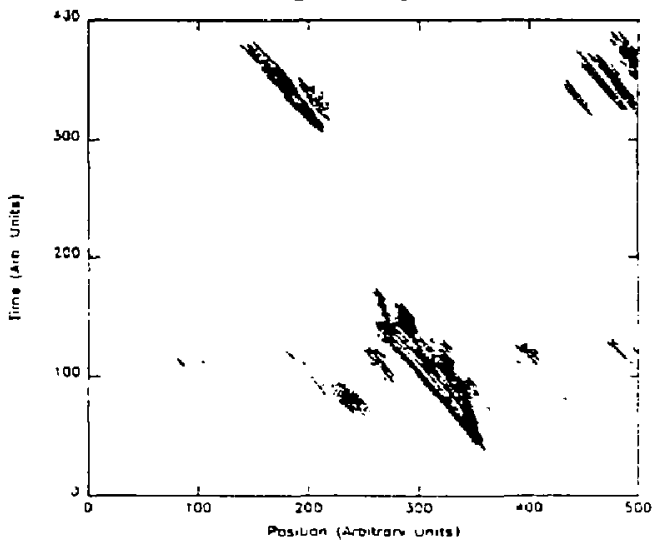

Figure 12. Sample B-scan of weld and flaw. The streaks near 100 on the time axis are echos from the weld crown through the water (hence not relevant). The streak at 300 to 375 is a $5 \%$ artificial flaw. The echos on the right side are from defects seen in Fig. 14. Note that some noise visible in Fig. 14 has been eliminated, i. e., the flaws are easier to see in this representation than in the contour plot of Fig. 14. 
The image in Fig. 12 shows a vertical crack and shows the complexity of the signals obtained from defects. At first one might be tempted to think the data representation in Fig. 10 would be easier to use but this ignores the extra information present in the echo dynamics. This extra information is needed to distinguish falșe signals from the weld bead from real defects and provides information to be usen in pattern recognition.

\subsubsection{Flawed welds}

Weld and heat affected zone defect manufacturing was tried in Type 304 stainless steel. The defects were created by machining lands ( 1 millimeters in 10 millimeters thick plate) in the weld preparation (Fig. 13) which allowed a preliminary assessment of the difficulty in manufacruring small defects in a typical material and closure joint.
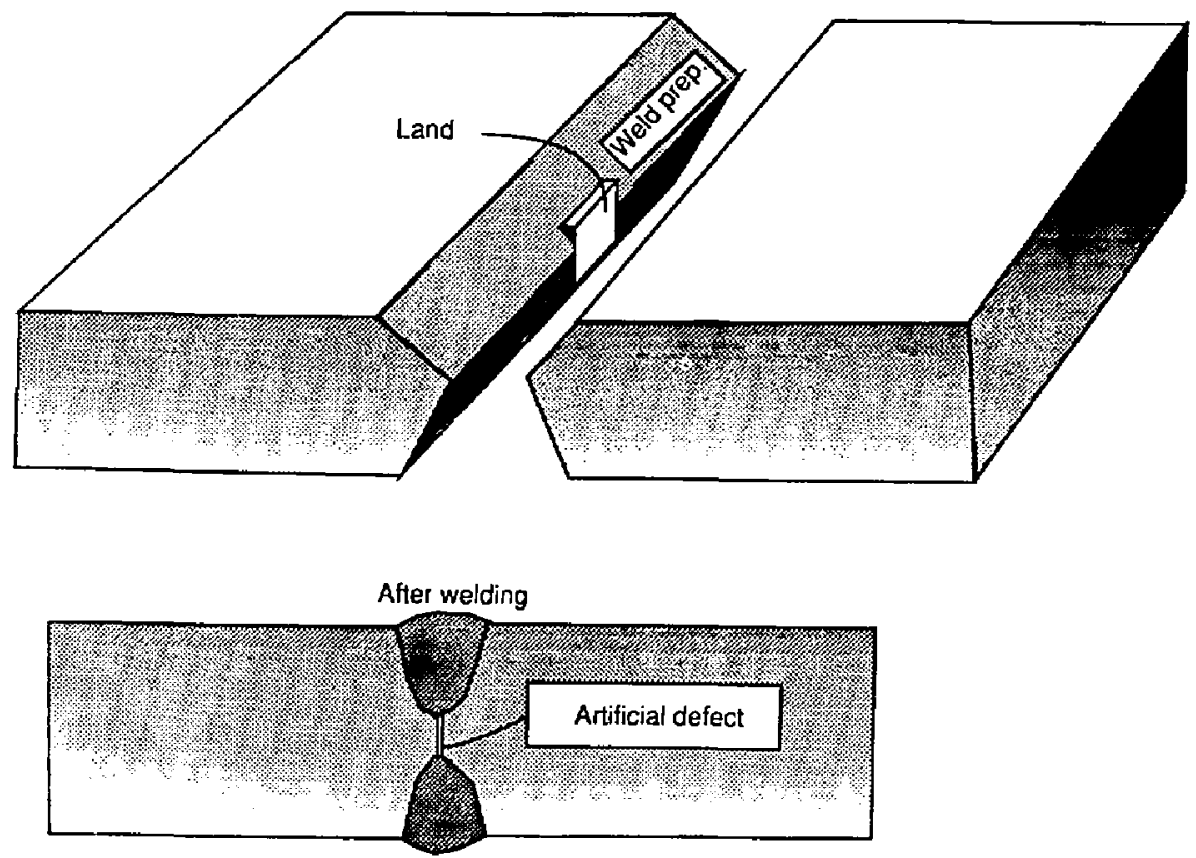

Figure 13. A preliminary method of flaw manufacture.

The ultrasonic and radiographic data on these welds show the defects to be much larger than the 1 to $5 \%$ sizes sought. The larger defects are not as interesting since they can be detected and sized reliably by ultrasonic testing in most candidate alloy and joining methods. A typical C-scan of one of these welds is shown in Fig. 14. This simple method of 
manufacturing realistic defects in welds will require more development wo be able to meet tils needs of the waste closure volumetric inspeclion system.

\subsubsection{Large depth of field lens}

Transducer design was begun and large depth of field sansducers were obtained and tested. The use of large depth of field ransducers is independent of the other methods described here and can be combined with them |14|. Large depth of field is desirable because the flaws remain in focus through a larger thickness. As with a camera, a telephoto lens can see small objects, but if the depth of field is too shon, then the lens must be refocused at many different depths to detect the same size object through the depth of material. The index of refraction (ratio of the sound speed of material to couplant) of steel, and most metals, is approximately 2 for shear waves and 4 for longitudinal waves. Most optical materials have an index near 1.5; therefore, imaging with sound is analogous to but more difficult than optical imaging.

A beam profile of a two-megahertz transducer is shown in Fig. 15. The depth of fiedd, as measured to the full width half maximum point (FWHM), is 15 millimeters in water or approximately 7 millimeters in steel for shear waves. The FWHM is the width of the sound beam when the amplitude is half the maximum amplitude. $A 1$ centimeter weld would require two passes with this transducer to be able to maintain focus through a 14 millimeter metal path, approximately a 45 degree shear wave. Two passes of the transducers can be performed rapidly or the number of transducers can be doubled to maintain inspection speed. Even larger depths of field appeas possible. The current design also produces substantial acoustical power, which is an advantage in lossy materials such as stainless steel welds. 


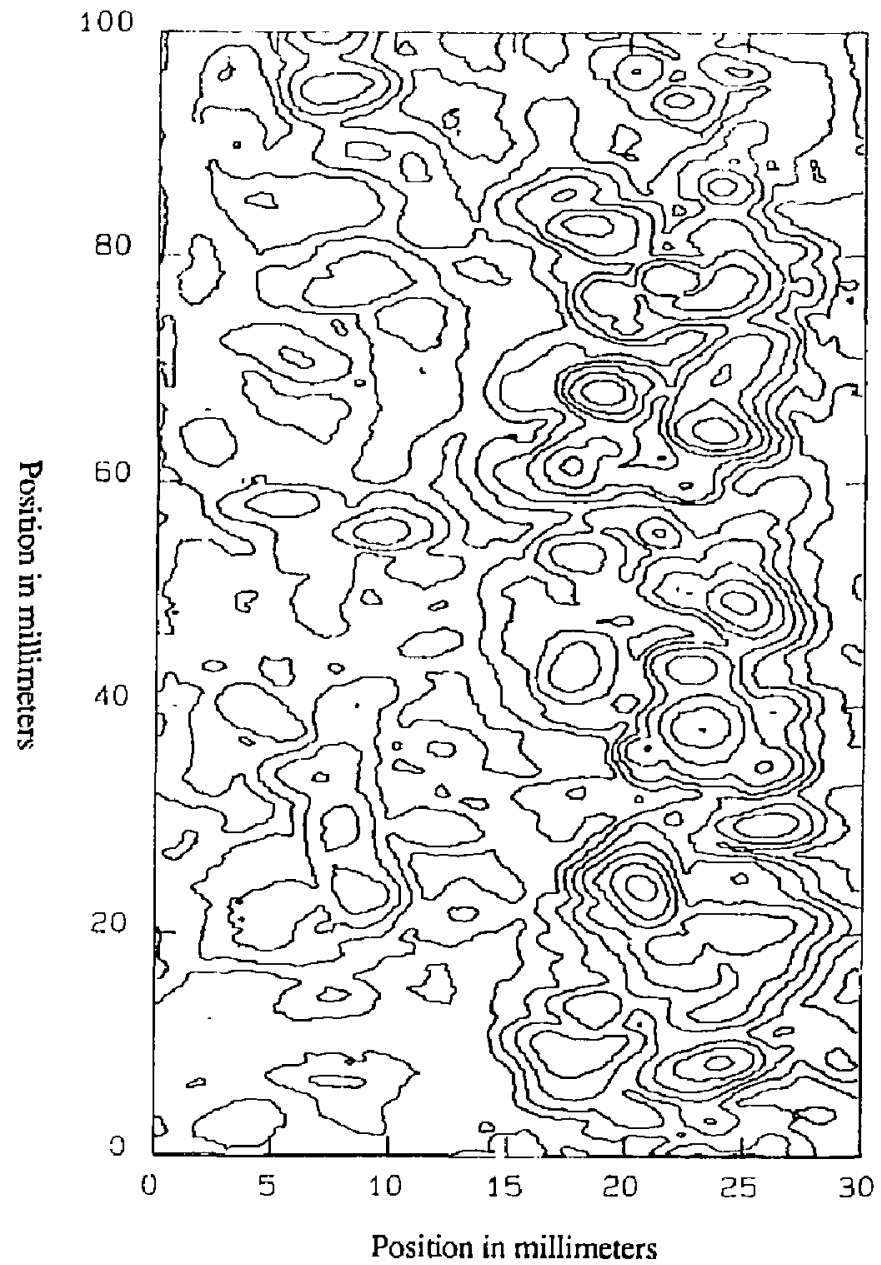

Figure 14. C-scan of flawed weld. The weld is in the center and artificial defects are on the right. The contour levels are the same as in Fig. 10. Note the difficulty of distinguishing flaws from noise. Much of this noise is from the weld crown and can be separated from flaw signals in time (Fig. 12).

The use of large depth of field transducers has advantages over SAFT for wall thickness less than approximately 15 millimeters. To understand why, one should realize that the synthetic aperture must be made from sound that actually penetrates the material. The practical beam divergence is determined by the combination of mode conversion at the interface and the critical angle for the mode being used. For an angle beam transducer, this limit is in the range of 35 to 45 degrees so that the maximum width of the sound beam is approximately the thickness the sound must penetrate. In materials less than 15-millimeters thick, the largest synthetic aperture that can be created is limited to 30 millimeters or so. 
Conventional transducers to 50-millimeter diameters are commercially available and SAFT cannot improve on them. The use of a lirge depth of field reduces the time penalty for the conventional transducer since a few transducers can focus through the entire volume of material. SAFT still contains some valuable methods that will be used on this activity since it straightens out the B-scan image and makes the sound image look like the part (see Secti.n 3.1 on SAFT). This process essentially converts the individual A-scans obtained into a malp of spatial coordinates instead of time coordinates.

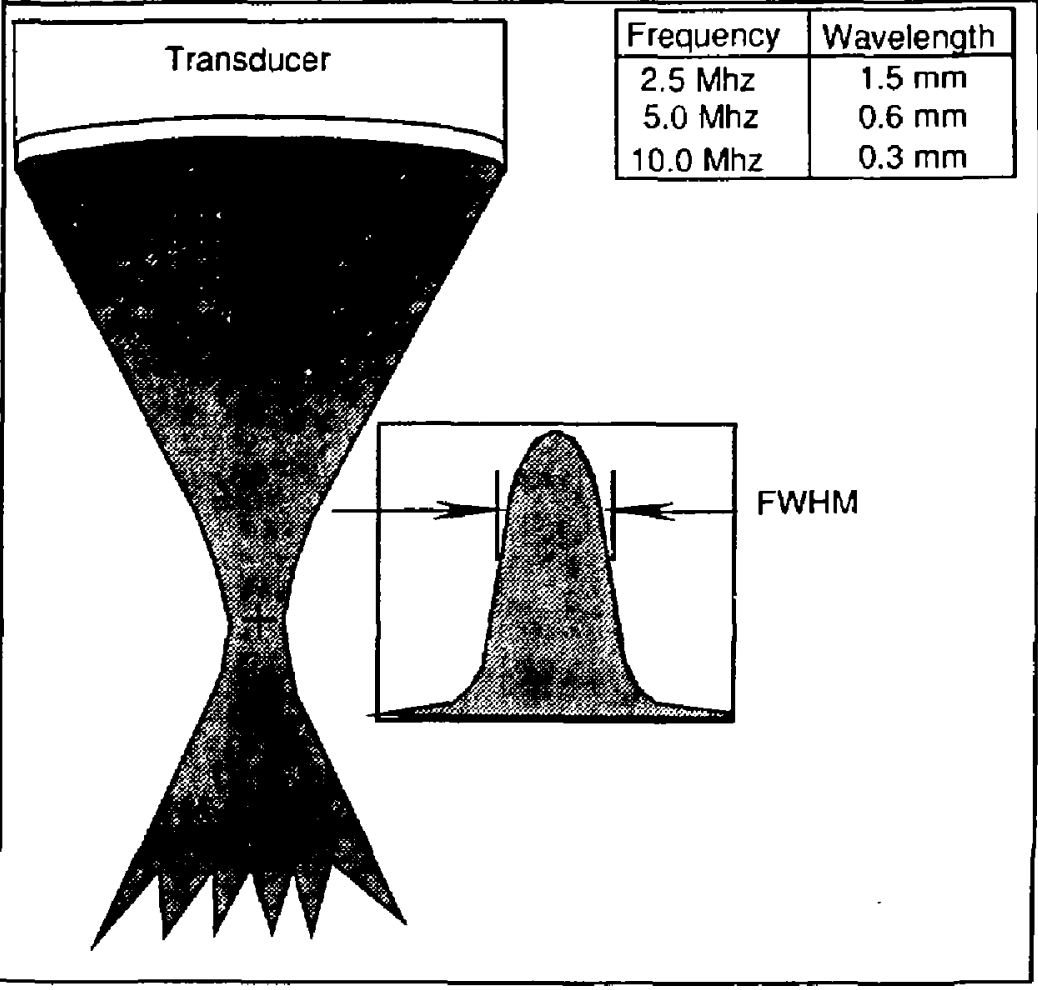

Figure 15. Beam diameter and the definition of Full Width at $\underline{\text { Half }}$ Maximum.

The use of large depth of fjeld lens is planned for use in this activity and requires only minor development. 


\subsubsection{Diffraction-based methods}

Diffraction of ultrasound from cracks has been used to size flaws more accurately than conventional test methods in austenitic weld metals for nuclear piping [16,21]. Information exists in the acoustic field that has been diffracted from a flaw that could be used to distinguish flaws from scattering from inhomogenieties in the weld metal. The sound reflected from the weld metal is dependent on the scattering from the microstructure of the weld metal and beam distortion. The distortion is caused by the variation in sound speed in the material from place-to-place caused by preferred orientation. The changes in speed refract the sound beam so that it travels in a direction different than anticipated.

Scattering is caused by the same preferred grain orientation that causes distortion but on a scale that is close to the wavelength of sound employed. The importance of scattering and beam distortion will be dependent on the selected closure process and material. The importance of these phenomena is, therefore, not yet known except for welding of Types 304 and 316 stainless steels and of Alloy 825, which are known to evidence this type of behavior. Well-developed techniques are available in ultrasonic inspection technology to solve such problems in these three materials.

Information on scattering is difficult to obtain with conventional test systems because the geometry of two transducers cannot vary arbitrarily to obtain information on the scattered field. The Ultrasonic Test Bed is designed to provide this capability and will be used to obtain scattering information on artificially manufactured flaws and closures, which should lead to an improved understanding of the diffraction and distortion caused by the anisotropic weld metals envisioned for the closure weld.

Analysis of anisotropic weld metals is much more complex than in isotropic materials (ferritics for example), and we have sought tools to allow improvements in this area. $L$. Adler [17] has produced software tools that we have selected for use in this activity because of their potential ability to predict the sound path in anisotropic materials.

Software developed by J. Opsal [18] and C. Visscher [19] to allow detailed scattering calculations from flaws will also be used. The codes have been installed on LLNL computers and will provide a theoretical framework for use of the Ultrasonic Test Bed (UTB, see the Appendix for a discription of the UTB). 
Statistical pattern recognition algorithms such as Automatic Leaming Networks have been used with considerable success in nuck ar piping weld inspection. These methods use statistical techniques to estimate how to remove interfering signals and to obtain useful measurements. The basic method uses known flawed materials, with known desired signals, to train on or learn the difference between flaws and noise signals. The result will be a signal with the interfering or noise signals removed and only significant signals remaining. Existing software at Sandia National Laboratories has been successful at improving inspection in austenitic weld metals $[20]$ and will be used to explore the applicability of these methods to the inspection of the closure weld in conjunction with diffraction-based methods using the UTB.

\subsubsection{Synthetic aperture focusing technique}

The thickness of the container wall is approximately 10 millimeters; therefore, real transducers can be larger than the synthetic aperture that could be calculated. Transducers with depths of fields comparable to the container thickness are available so that focused images can be obtained without the calculational burden of the SAFT method. For this reason the advantages of this method for the closure examination are limited. This would be less true if the thickness increased to 25 millimeters and SAFT would be the prefered method with thickness greater than 50 millimeters.

This method does have the ability to unfold the B-scan data so that the image looks more like a cross-sectional view through the weld or closure. The improvement in interpretation of these less distorted images might be desirable for closure NDE.

The SAFT computer codes are available if needed for closure NDE application. Use will be made of the display routines.

\subsubsection{Focused methods}

The ability of focusing to improve the ultrasonic examination of weld metals can be understood from the nature of scattering from the austenitic weld metal" . The scattering site is known to be a significant fraction of the weld thickness (more than $10 \%$ of wall

\footnotetext{
- The container material has not been selected but the ultrasonic propenics of the other candidate alloys are sisnilar to austenitics and they are used as an example of the types of problems to be encountered und beciause a large experience base exists in solving ultasonic inspection problems in this type of material.
} 
thickness) and reflects a fixed amount of sound back to the transducer. The amount is determined by the acoustic impedance (the sound speed multiplied by the density) mismatch in that region, or by the diffraction properties of that region, or by both. The sound amplitude reflected from a low density defect is usually much larger than the scattered sound because the impedance mismatch is greater. As the sound beam is reduced in size, the percent of the sound beam area intercepted by the flaw increases. The actual amplitude reflected is the product of the acoustic impedance mismatch of the flaw and the area of the defect as a percent of the beam area at that point. Since the beam area is reduced, this latter percentage is increased for the flaw but not for the scattering site since the site already covers $100 \%$ of the beam. This method has been used to improve nuclear piping weld examination in Europe and the United States [13]. Figure 16 is a beam profile of a large depth of field transducer.

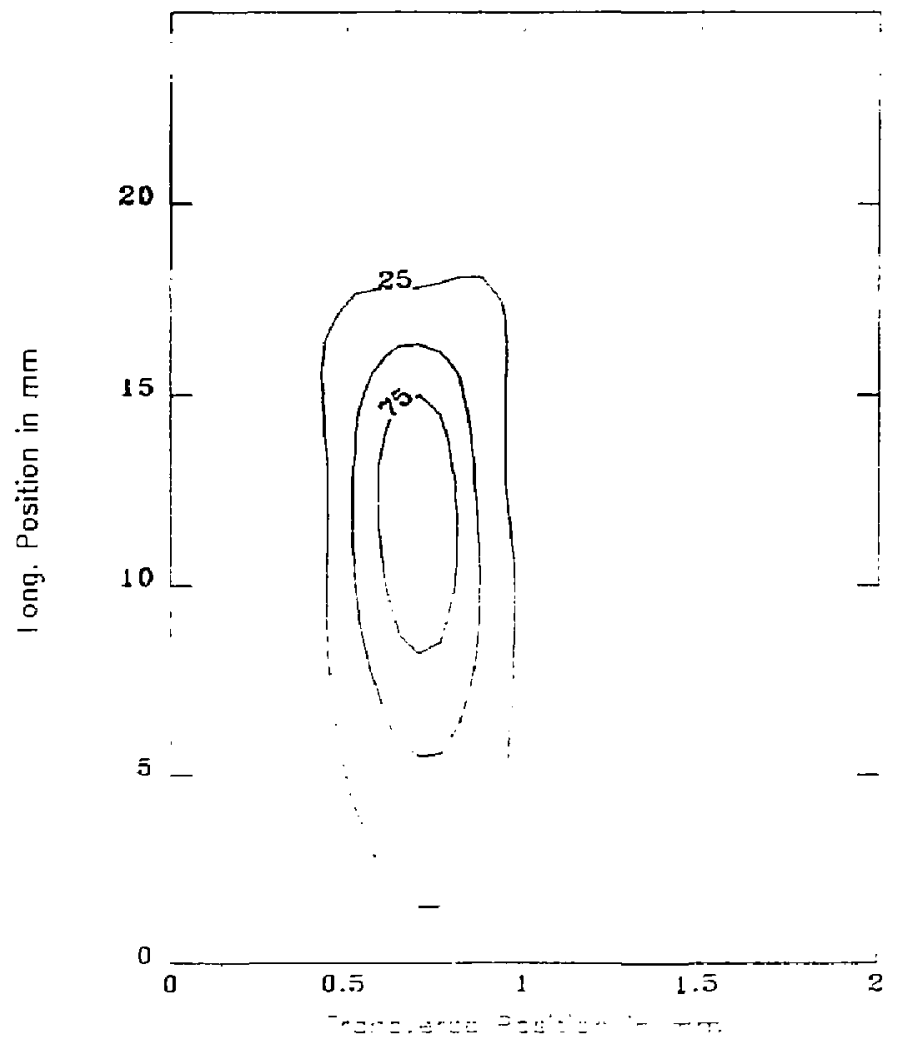

Figure 16. Beam profile of a large depth of field lens (14 millimeters in water). The center contour defines the FWHM value which is 1 millimeters for this lens. 


\subsubsection{Longitudinal waves}

Longitudinal waves have been shown to be effective in reducing the scattering and beambending characteristic of austenitic metals $[22,26,28,30]$. The presence of a shear wave with a different speed and angle than those of the longitudinal wave is a complexity (Fig. 17) that must be overcome to use this method, but is justified to take advantage of the superiority of the longitudinal wave mode. The simpler the weld shape, the easjer it is to apply longitudinal wave methods.

The means of dealing with two wave modes is dependent on the difference in their sound speed. The difference in sound speed causes signals from the longitudinal wave to arrive sooner. The speed difference also changes the angle of refraction; therefore, these signals travel a shorter distance for shear modes and the time difference is not as great but the amplitude frequently is very small. The irregularity of shape (characteristic of welding) can make this interpretation more difficult if the weld shape reflects shear waves so that they arrive at the same time a longitudinal signal is expected from somewhere else. Hence, shape and roughness of the closure can increase the complexity of the inspection or can make interpretation more complex.

The reasons for superior results with longitudinal waves is not well understood, but their superiority has been well established [2]. Evaluation of longitudinal wave inspection will be pursued for the closure NDE activity. 


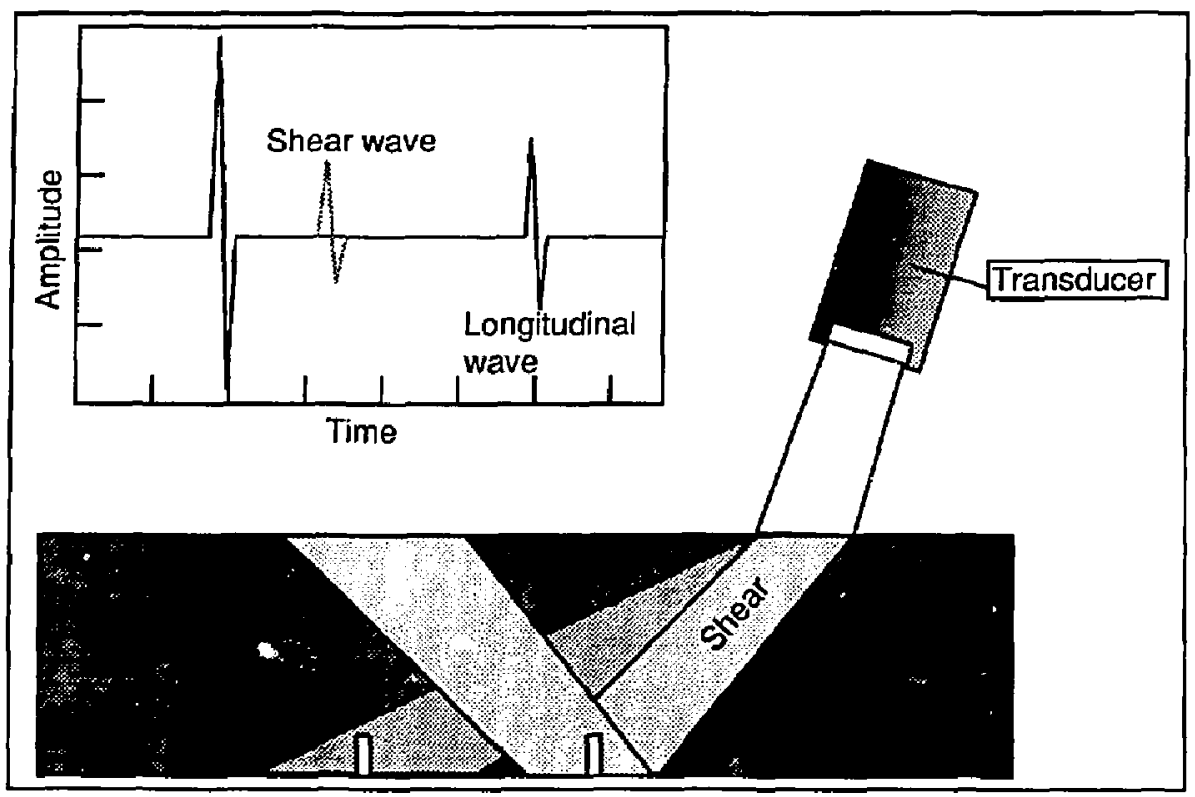

Figure 17. Use of a simple longitudinal wave angle beam showing the separation of the longitudinal and shear waves because of their different sound speeds.

\subsubsection{Alternative volumetric techniques}

\subsubsection{Positron tomography}

Positron tomography is a well-developed medical technology. A positron emitter is distributed so that its concentration corresponds to the feanres of interest. Imaging is accomplished by using the fact that positrons travel only a short distance before de-exciting and emitting two 0.5 megavolt ganma rays at 180 degrees to each other. This symmetrical emission allows a ring of detectors to form a tomographic-like image using time coincidence methods. Current medical methods result in an image resolution of approximately 1 millimeter in biological tissues.

When using this technique with a waste closure weld, a means of introducing a small or trace amount of positron emitter would have to be found. Since the high background radiation of the waste has a broad spectrum, a counter that looks only at the 0.5 megavolt decay of the positrons has a high level of exclusion for the background. The amount of 
positron activity needed under these conditions is substantial since the energy selectivity cannot achieve much more than a million-io-one improvement. If we assume the activity of the waste is equivalent to a megacurie, then one curie of positron emitter is needed. At current specific activities, several to a hundred grams of positron emitter would be needed. This level of contamination is of concern from a matenal point of view; i.e., the available positron emitters are not benign weld constituents. Additionally, the cost of the material would be prohibitive (thousands of dollars per container).

The ability of this method to detect crack-like defects is unproven and it would not be expected to be better than a radiographic method since it depends on similar physics to form the image. This leaves positron tomography a lower priority candidate for the NDE of the container closure.

\subsubsection{Eddy current volumetric techniques}

Eddy current of welds thicker than 6 millimeters is potentially sensitive to defects in welds in smooth-surfaced materials. Eddy current as a backup method for ultrasonic exists since the potential sensitivity to detect cracks is better than the alternatives (see Table 1). Eddy current of such complex materials (complex from the eddy current point of view) requires the use of multiple frequencies combined with complex signal processing to renove the effects of variation in conductivity and magnetic properties.

The use of eddy current would likely require the weld outer surface to be relatively smoother than ultrasonic methods require. The crack-like defect sensitivity is approximately $10 \%$ and this could also be a problem if $a$ should be smaller than this value. Eddy current is a backup method for this application and will be pursued in concert with the surface inspection described in Section 4.2.2.

\subsubsection{Electromagnetic acoustic transducers}

The use of Electromagnetic Acoustic Transducers or EMATs is attractive since no paste or liguid couplant is required. The technology is currently well developed and EMATs have been used for a variety of applicitions. Howcver, their use in highly lossy materials like

\footnotetext{
- Eddy current may be used for volumetriç inspection of austenities and non-ferrous alloys under 1 he ASME. Rosiler and Pressurc Vessel Code if the thickness is less than 6.5 millimelers.
} 
austenitic stainless steel and copper based welds is difficuls because the ir efficiency is very poor in comparison to conventional transducers. The difference in efficiency is generally greater than a factor of 10 . This large penalty represents a significant risk because the weld zones require high intensity sound for penetration and because EMATs with the required bandwidth and focal depth have not yet been demonstrated. The high radiation resistance of EMATs is not a significant advantage since conventional transducers have been operated successfully in close proximity to spent fuel in light water reactors. The actual weld material selected will influence the potential applicability of this method since methods of focusing are theoretically possibte and materials with a high conductivity improve the efficiency of this methat. The removal of surface weld crowns or similar discontinuities on the surface would be required to apply this method.

\subsubsection{Laser generated ultrasound}

The use of laser-generated and laser-receited sound is artractive since it has high bandwidth and better sensilivity than EMATs, although still less than conventional trinsducers. This method has barely emerged from the research stage and is not yet a commercial venture. The use of remote lasers requires the use of optical fibers that can darken in a radiation field. A number of difficult problems would need to be researched before this method could be used successfully on the container closure. Hence, laser is an interesting method with potential if research into its use by others is successful.

The use of focused beams with laser generation and detection has not been demonstrated but is possible with phased array [23] technology. A proposed laser system is shown in Fig. 18. This system uses several undemonstrated innovations. One is the use of a fiber optical amray to transmit and receive the sound and the other is the use of coaxial interferometry to use this same array to receive the sound. Both innovations are of conjectural performance, placing this method in a more speculative category than EMATs. The fibers would also be subject to radiation darkening, and although low darkening fibers have been developed, this could be a factor in the high radiation environment near the container. 


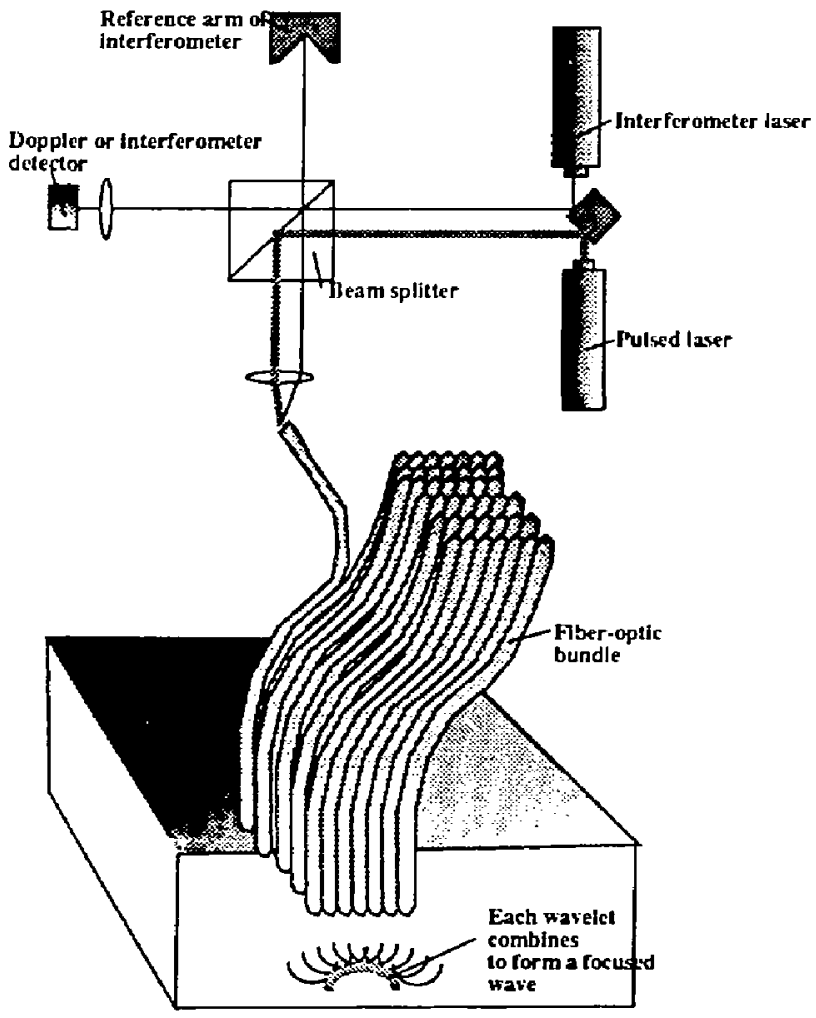

Figure 18. A laser ultrasound phased array. The interferometer and pulsed laser optical system (upper portion of the figure) must be duplicated for each fiber.

\subsubsection{X-ray radiography}

The high radiation levels of the container make $x$-ray radiography an unlikely candidate for container closure NDE. The likely sensitivity to crack-like defects is poor. X-ray methods will not be pursued in this activity.

\subsubsection{Other methods}

The use of air in the form of a gas that transmits sound is very attractive but also presents some problems. The only method for making magic gas is to pressurize argon to 20 atmospheres. The gas transmits sound well at this pressure, but a very low acoustic impedance prevents the sound from entering the high impedance metal of the container. This effect, combined with the high pressure required, makes this method less attractive; 
however, the potential for use of helium at moderate pressure exists. Gas coupling developments will be monitored for potential use in closure NDE.

\subsection{Surface Flaw Detection}

\subsubsection{Liquid penetrants}

The use of liquid penerrants is well established for the remote inspection of welds [8]. This method is messy (various liquids must be applied and removed) and requires a complex system for remote application and interpretation. This method has been selected as a primary inspection method because it can be applied with minimum preparation to aswelded surfaces.

This method will require that the closure area be extensively cleaned after application since there is no way to assure that the penetrant and its associated chemicals are benign in the emplacement environment. Small flaws (the exact size is dependent on the alloy, penetrant procedure, and penetrant materials) will escape rejection by this method and by ultrasonics. Hence, removal methods must be able to remove these residual penetrant materials both from the surface and from any flaws that might be present but escape rejection. Because the time period that the container will be subjected to any residual penetrant chemicals is very long, a test of complete removal is required.

Penetrant application, therefore, requires the development of remote application and interpretation methods and methods for cleaning and testing cleanliness for closure NDE. These activities will be pursued in the NDE activity.

\subsubsection{Eddy current}

A chance exists that the outside surface of the weld will be machined smooth to enhance both volumetric and surface inspection. The we of eddy current methods is well established for surface examination for austenitics, high-nickel alloys and copper alloys and can at least duplicate the sensitivity of liquid penetrants but without the need for the liquid chemical penetrants [7]. This option allows combination of the ultrasonic and surface inspection methods since the eddy current coils can be added to the ultrasonic search unit and the scan pattern adapted to both. Elimination of the penetrant application, cleaning, developer, and 
recleaning steps of liquid penctrants secms worth while if an adecluate surface can be achieved within the other constraints of the closure method

As a surface method, the problems associated with volumetric eddy curremt inspection can be eliminated by concentrating the eddy currem in the surface of the materiat. This allows the $10 \%$ sensitivity of the volumetric lechnique (lable 1) to be much smiller since the depth the eddy current penetrates ean lxe selected. The depth is controlled by raising the frequency to lower the penetration, and if the depth is only $10 \%$ of the container wall] thickness, then the eddy current method is $1 \%$ sensitive on a through wall basis.

Effort on this method will depend on the closure method, on the contajner matterial, and on the outer surface finish.

\subsubsection{Surface acouslic waves}

The generation of a surface wave at the first critical angle can be used to detect cracks with sensitivity equal to dye penetrants. This also requires a smooth surface. Since the ultrisonic volumetric and SAW inspection can be combined which is potentially advantageous. Another potential advantage is that SAW is relatively immune to conductivity and material variations in the container (eddy current can te sensitive to these effects). SAW is a backup method because it is relatively slow. This method reyuires a snooth surface finish; therefore, its use will require a smosth outer surface.

\subsection{FUTURE DEVELOPMENT}

The following describes proposed development and testing activities to be carried out in support of Container Closure NDE Process Development. The activities are of (wo classes: those that can be done independently of other tisks and applied to whichever materials and closure processes are selected, and those that must be done in concen with materials selection and weld process development. 


\section{Table 3. Independent and Dependent NDE Activities}

\begin{tabular}{ll} 
Independent Activities & Section \\
\hline L.arge depth of tield lets & 5.1 \\
Coupling methods & 5.2 \\
& \\
Dependant Acrivities & Secrion \\
Flawed closures & 5.3 \\
Remote system design & 5.4 \\
Radiation resistant components & 5.5 \\
Remote system design & 5.6 \\
Artificial intelligence and data acquisition & 5.7 \\
Equipment Calibration & 5.8 \\
Quality Assurance & 5.9
\end{tabular}

\section{$5.1 \quad$ Large Depth of Field Lens}

Large depth of field lenses will benefit any closure method and can be pursued independenty of other activities. Improvements in the ultrasonic depth of field are also possible and will be pursued. Such improvements include doubling the depth of field and using large transducers to penetrate more lossy material. These improvements will benefit all materials and closure methods.

\subsection{Coupling Methods}

Since coupling fluids are an inconvenience, this area focuses on reducing their impact or eliminating them. Two coupling methods are defined with various advantages and disadvantages: they are the bubbler and the clamshell, and they are described in the following sections.

\subsubsection{Bubbler}

The use of shoes, squirters, and bubblers is well established for remote inspection. The shoe technique, which is popular for nuclear piping weld inspection, is shown in Fig. 19. This method requires the use of a paste-type couplant on the container surface. The main objection to this method is the potential for contamination. These materials have been used extensively on alsteritics and contilin trace amounts of low melting point elements, halogens, and sulfur compounds. Still, the long lifetime of the joint argues for caution in applying any materiad that cannot be easily removed or that nught leave a residue. These materials are easily removed with water: but if water is acceptable, the use of other methods 
might be more attractive. Another potential difficulty is degradation of the paste in the high radiation field that might make the pastes tnore difficult to remove.

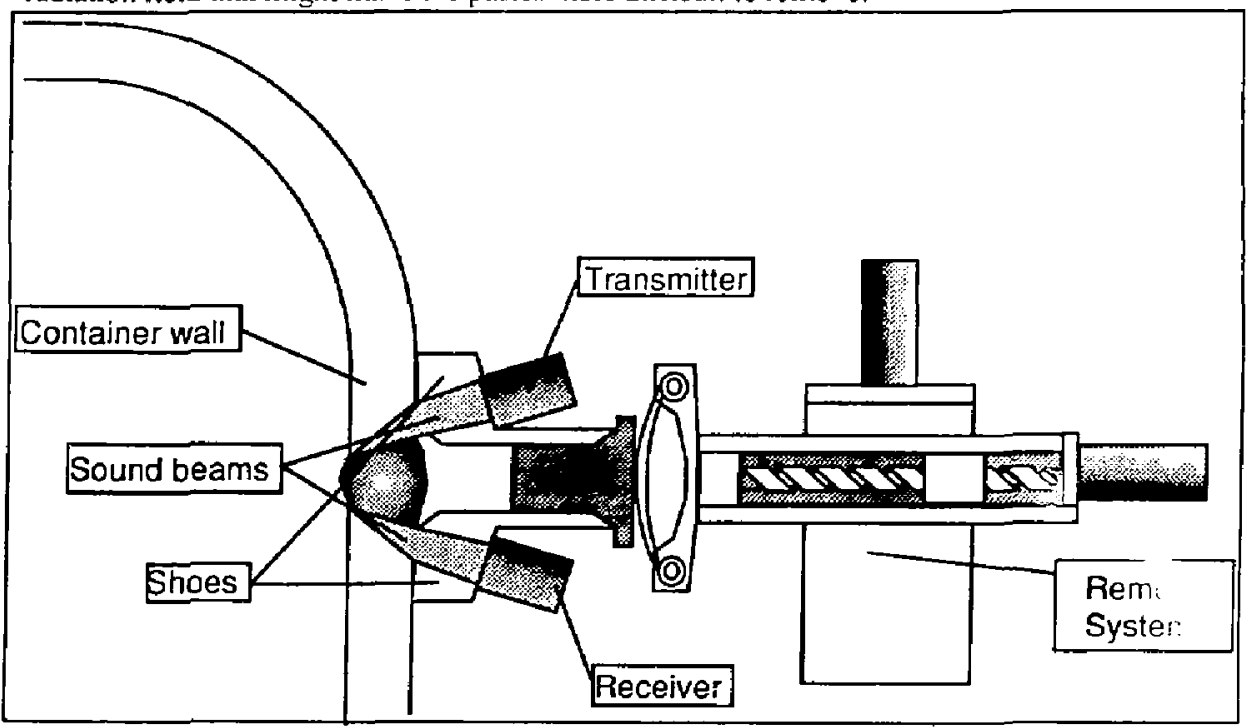

Figure 19. Inspection with a pair of shoes. Note the difficulty of using two transducers because the shoes cannot ride over the weld crown.

The use of squirters is based on using a waller column to guide the ultrasound into the part. For the focused inspection proposed here, this method is not suitable. Modifying the squiner to be suitable results in a bubbler, which is illustrated in Fig. 20. The bubbler has several advantages over the shoe; a paste is not required, which reduces the potential for radiation damage since fewer organic-based materials would be used in a bubbler.

The need to seal the interface between the bubbler and the container is generally achieved with an elastomer; therefore, a potential area for radiation damage exists but is clearly less than that of a plastic shoe. An additional potential difficulty exists since the bubbler must seal on the weld and the weld night be irregular. This difficulty can be solved either by machining the weld crown smooth or by using a more compliant (and more radiation sensitive) elastomer membrane. It should be mentioned that a bubbler will leak and water will need to be managed so as not to present problems for other parts of the system. A leading difficulty is that the water could be contaminated and would need to be discarded. If the closure is leak-tested first, managing the water siould not present a major problem but will require careful engineering. The bubbler might also present flow-induced noise 
problems since the couplant flow frequently has to be very fast to compensate for leaks; this can distort the ultrasonic beam and influence the test [24].

\subsubsection{Clamshell}

An innovative method to allow inspection without the need for elastomers is illustrated in Fig. 21. The use of a clamshell ring to hold a tank of water arnund the container has some advantages. Because flow rates to maintain the couplant in a clamshell are less than those in a bubbler, turbulence is less likely to be a problem. Another advantage is that the transducer array can occupy a larger volume, and the clamshell can accomodate a larger volume of transducers and the water they require. The water in the clamshell does not move; therefore, its volume and weight can be much larger than a bubbler without slowing the speed of ultrasonic system (because the bubbler must be moved with the transducer). This method is clearly more complex to set-up since the clamshell weighs more and would cake longer to position than a bubbler. This method is currently the preferred method because it allows use of the planned inspection method with littie risk of ultrasonic difficulties. 


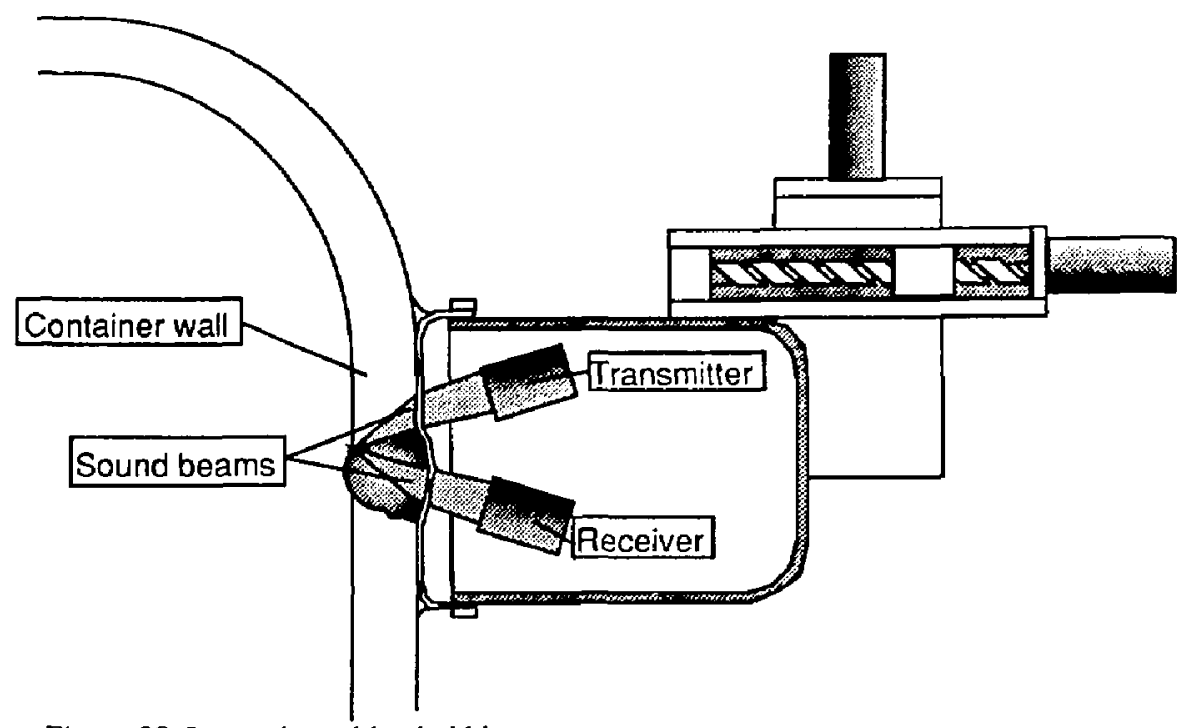

Figure 20. Inspection with a bubbler.

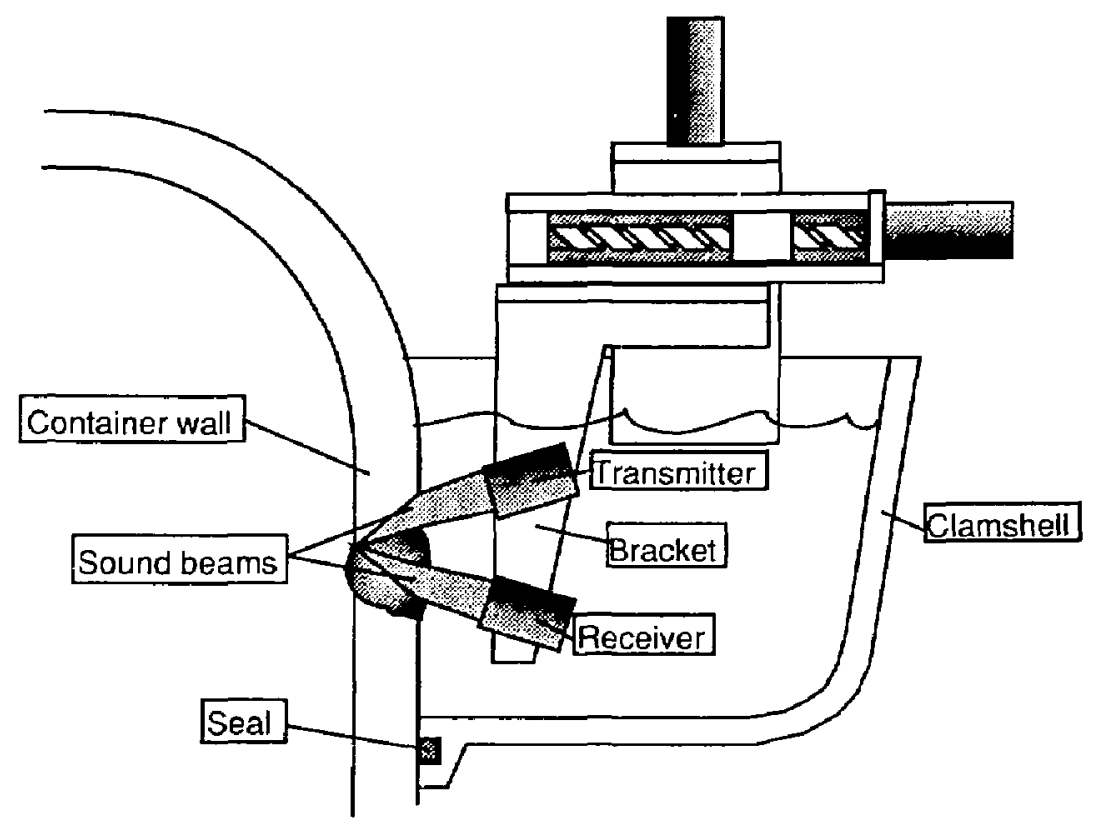

Figure 21. Use of a clamshell to hold the couplant. 


\subsubsection{Electromagnetic acoustic transducers}

Electromagnetic Accoustic Transducers (EMAT) do not require a couplant and could allow elimination of the couplant altogether. Pursuit of this option is dependent to some extent on the alloys selected for the closure and to a lesser extent on the closure method used. Factors that limit the use of EMATs include:

- Low conversion efficiency from electrical to mechanical energy and vice versa. This factor is very severe in austenitics but not as severe in higher conductivity materials such as copper-based alloys. Hence, EMAT development is more attractive for those alloys.

- EMATs have not demonstrated spherical focusing at practical power levels, principally because of the above-mentioned inefficiency combined with the relatively complex coils required.

- The use of an eddy current means to send and receive sound in the materials makes this method heir to the same problems eddy current experiences, which include difficulties with as-welded surfaces and potential variations in conductivity or magnetic properties.

The elimination of the couplant is worthwhile if liquid penetrants are not needed; therefore, pursuit of this method is dependent on a smooth surface, which would allow use of eddy current or SAW approaches to surface inspection. Under these conditions, EMATs could be used to generate both the volumetric inspection and the SAWs for surface inspection. Eddy current could also be used with the EMATs for surface inspection.

\subsection{Flawed Closures}

Manufacturing flaws must be developed after material and closure methods have been selected. Development closures, which have deliberate or inadvertent flaws, can be used but frequently are not available because they either are destroyed for process development reasons or are of unknown size and shape. Hence, to allow qualification of the NDE, methods of manufacturing realistic flawed closures will be required. 
Preliminary work shows that realistic irack-like thaws that are smadl enough to serve as yualification specimens are not casily nanufactured in welded Type $3(1+4$ material. The difficulty of manufacturing fliws in Type $3(1) 4$ welds makes it reasonable to assume that other closure methods and materials might also present difficulties.

Since the flaw manufacturing method is difficult to ctefine until the closure method is selected, an exact plan cannot be established. If weiding is selected, then methods refined from the preliminary method described in Section 4.1.1 can be used. Refinements that will be necessary in this circumstance include: (1) pliting the lands with a neutron absorber to allow neutron radiography to define actual flaw size and shape and (2) developing the weld technique used to make the defects. Variation in the selected weld process to produce defects will also be investigated, but difficulties have been encountered in producing known flaws by this method [24]. Realistic flawed samples will be produced by inducion of stress corrosion cracking and therral fatigue methods as well [14].

\subsection{Radiation-Resistant Components}

Radiation-resistant equipment for NDE of the closu:e is currently available commercially, and little development in this area is required. Reliable remote systems cannot be achieved without careful testing of components. Such testing will be required for the closure NDE equipment. More testing might be identified as design of the remote NDE system proceeds. Irems that will require radiation and temperature testing include:

- The ultrasonic uransducers.

- Remote components that come in close proximity to the container.

- Any seals or membranes used in coupling.

- Any paste couplant that might be used.

- Electrical motors.

- Encoders and sense switches.

- Drive components thall include lubricants or plastics 


\subsection{Remote System Design}

Remote system design must be coordinated with the repository hot cell and disposal container closure system. Special attention will be paid to the ongoing closure process development activity to assure that appropriate system interfaces are maintained. A specific interface might be required if the selected closure system and NDE system are combined (a choice that has not yet been made). The interfaces illustrated in Fig. 22 assume that they have been combined.

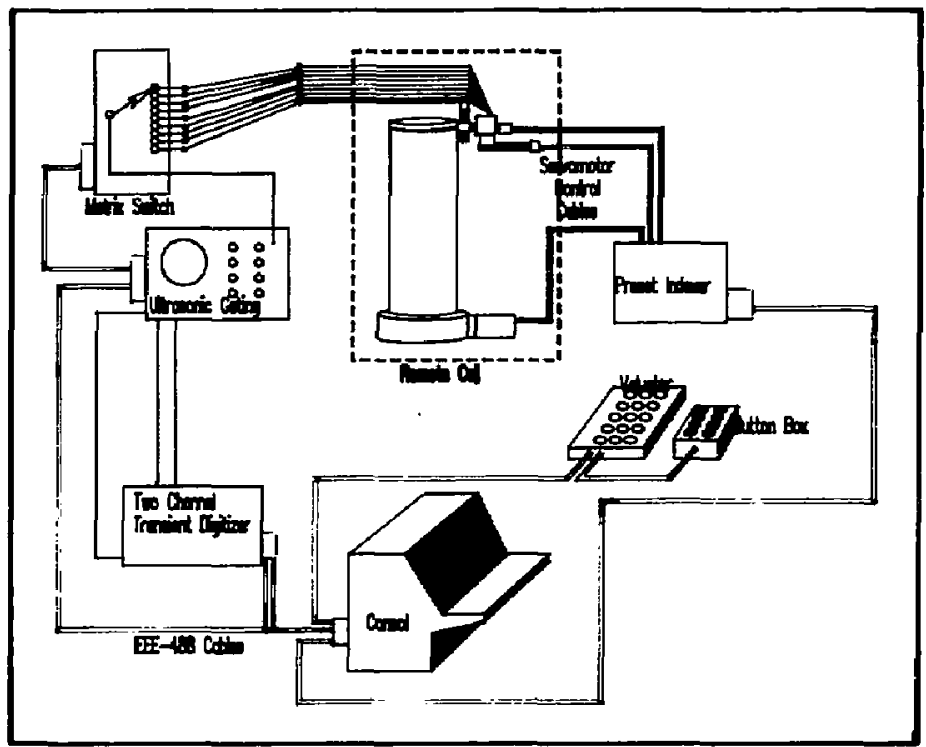

Figure 22. Conceptual design of one proposed remote NDE system.

Figure 22 illustrates two likely interfaces: (1)the dual use of a container rotator both to make the closure and to perform the NDE and (2) the electrical connection to the NDE remote inspection system. In the case of only an electical connection to the NDE system, the interface is independent from the closure system but the two systems could coexist in the same cell. 
Some interface areas to be addressed in the case of combined NDE and closure systems include:

- Can the rotator be run conveniertly by the NDE system and the closure system and with adequate resolution and accuracy for both?

- Where and how is the NDE remote system mounted in the cell, and how much room, weight, and electrical services must be provided?

- How will the NDE remote system be brought into proximity on the closure, and what features are required to make room for it?

- If couplants and dye penetrants are used, how are they handled and what handling services will be required?

- What space and facilities are required for the external cell equipment, and what is the maximum distance they can be located from the cell?

- What motion envelopes for the NDE remote system will be needed to a void potential interferences with the other equipment that is in the cell?

These interfaces will change depending on actual logistics of closure and the details of how NDE integrates into the closure process. Some possibilities include:

- The closure is done in a separate cell from NDE. This would simplify the interfaces but would require moving the container between closure and NDE.

- The closure remote system can be integrated with the NDE remote system by using different end effectors (the mechanism you put on the end of the remote system to effect some special function such as NDE or welding). This will require a more intimate interface between the closure remote system and NDE remore system, which must be defined early. This approach has the advantage of allowing intermediate inspections of the closure (such as root pass inspection) if it should be desirable. This approach may reduce the amount of remote apparatus required. 
- The couplant migin not be needed, which would eliminate one intertice and simplify some aspects of r mote application.

Detailed interface specification will be required and will need to be coordinated with the closure method development and repository surface fucilities design. Many of these interface specifications cannot be written until the disposal container material and closure method have been selected.

\subsection{Data Acquisition and Artificial Intelligence Syatems}

The data acquisition is conventional and will use standard B-scan mode*. This requires only that the A-scan da a be acquired by standard digitizing equipment, as shown in Fig. 22. Since suck equipment 1 . currently avalable and software is currently in use for data acquisition from remote inspection systems, little development will be required to apply this technology to the remo : closure NDE.

Interpretation and signal processing are more complex. Experience has shown that considerable experise . required to interpret ultrasonic examinations. In addition, signal processing also req'sires substantial experience to process the data intelligently [25]. This expertise is currently being incorporated into expert systems that will be used by NDE personnel to perform si $i_{\varepsilon}$ nal-processing functions. Work is also proceeding in ultrasonic signal interpretation, and this work will potentially be useful in closure NDE evaluation. This work is not current $y$ part of this activity but will be used as a basis for developing the signal processing neede 1 for the prototype demonstration of remote NDE.

Hence, the closure NDE computer technology will need to be compatible with current object-oriented (arrificial intelligence) programming environments to take advantage of these developments. This wil allow use of ongoing programs and expert systems as well as building systems for closure use.

\subsection{Equipment Calibration}

No development is re puired to calibrate or qualify the closure NDE system. Once $a$ is selected and approprial thawed and unflarved closure samples are created, these processes

\footnotetext{
B-scan mode allows easy changes in signal processing and provides the highest accuracy data recording
} 
are straightforward. However the manutacturing of realistic thawed closures is not as straightforward; therefore, this effor is significant (see Section 5.3).

\subsection{Quality Assurance}

Quality assurance Level I requirements will be imposed. No development is envisior ed for writing procedures to comply with Nuclear Waste Management Program Quality Assurance Program Plan (NWMP QAPP). Standard calibration and qualification procedures common to the nuclear industry will be used.

An estimated 50 procedures will be needed for the development of the NDE methods. The actual repository prototype will require 75 to 100 procedures (based on the development procedures). Procedure preparation is therefore a significant part of the NDE development activity. Stringent document control is required by the NWMP QAPP; therefore, these documents must be prepared, reviewed, approved and revised through established channels.

\subsection{CONCLUSIONS AND RECOMMENDATIONS}

With anticipated closure methods and container materials, ultrasonic and liquid penetrants represent the best choices for closure certification.

If weld crown remova! is selected or becomes a requirement, then eddy current surface flaw detection and ultrasonic volumetric methods would be an altractive combination. Because the eddy current method requires scanning that can be easily accomplished with the ultrasonic scanning equipment, this choice would not impact significantly on development or design of the remote equipment for the closure certification task. Eddy current would require more development for a given alloy than would liquid penetrants.

The potential difficulties of applying ultrasonic testing are the uncertainty in the critical flaw size, potential anisotropy (from preferred orientation) of the closure microstructure, and inconvenience associated with the couplant. Ultrasonics can detect interior and surface flaws with sensitivities that are definable for Types 304 and 316 austenitic weld alloys (assuming that the process is similar to automated welds now employed in nuclear construction) but are uncerain with the other candidates because of the lack of experience with welding. Uncertainty of thaw sensitivity and reliability also exists for other joining 
processes because of a lack of berifiable experience with ulurasonic inspection of joints made by methods other than fusion welding or closures with other materials.

\subsection{Vitrasonic Methods}

The following items are milestone goals of the Container Closure Nondesurucrive Evaluarioni $N$ D E J Process Development. activity.

- Periect a means of making flaws in the selected closure method such that the flaws are representative and $\mathrm{L}:$ size of the flaws can be characterized. Produce a selection of flawed and unflawed closures adequate to allow qualifying both ultrasonic and surface methods to the SOS. POD specified in Goals (Section 2.3).

- Design, build, and test a radiarion-resistant, large depth-of-field lens for closure ultrasonic examination. Tests must determine both the mean time between replacement and the inherent drift uncer repository conditions to meet reasonable maintenance requirements.

- Characterize the ultrasonic properties of the selected closure material and closure method once subscale parts have been supplied by the other process development accivibies.

- Select a coupling method after

- Designing and testing but jler-based inspecrion in appropriate mock-up to test its ability to meet performance requirements and to resist probable radiation damage.

- Designing and testing clamsinell coupling in an appropriate mock-up to test its abiliny to meet reasonable isstallation requirements and its leak potential.

- Testing EMLAT performance, if copper alloys are selected. by designing and building a protonype system. a.7d tescing ultrasonic perfornance against the critical flaw size determined fe: the closure. 
- Design a full-scale prototype remote system in concen with the closure fabrication process development activities and with remote cell hogistics.

- Demonstrate a prototype NDE system of a model final closure under simulated repository conditions.

- Build a full-scale prototype and demonstrate NDE of final container closures at the repository.

\subsection{Surface Methods}

The use of dye penetrants does not represent a performance or remore application problem but does represent a potential contamination problem since the chemicals must be completely removed Hence, some additional work would be desirable if the outer surface of the closure can be made smooth enough. These activities are:

- Designing and testing an eddy current surface method.

- Designing and testing a surface wave method.

Both these activities require a relatively smooth surface and are dependent on the materiai and closure method used for the waste container.

Additional exploration of ability of cleaning to effectively nemove all penetrant residue will be required if the closure choice does not lend itself to one of the above methods. This study is dependeni $\mathrm{c}$ ? the closure method and material as well as the critical flaw size. The reason the flaw size is important is that the study must be able to determine that residual penetrant materials are adequately removed from the flaws that might remain on the container surface. The surface finish and oxides will also be imponant to cleaning and therefore must also be defined.

The activities necessary to cerify cleaning techniques are:

- Establish realistic control coupons containing crack-like flaws and appropriate surfice conditions for the closure material and method selected. 
- Dye-penetrant inspect these coupons with appropriate selections of penetrants and developers. Several types are potentially useful.

- 1radiate some samples to model the hot cell environment after penetrant and after developer application.

- Use appropriate surface chemistry techniques to determine potential residual chemicals from the cleaning process for each type of penetrant.

- Write procedures and specifications for the remote system to assure complete removal of penetrant chemicals in a hoc cell environment.

- Design and build a model of the remote penetrant system that is protorypical of real performance of a hot cell system.

\subsection{Research Areas}

The following areas should be monitored for possible use in closure NDE process development. Attention will be focused on the current literature and to programs at other institutions and at Lawrence Livermore National Laboratory that are potentially useful to the NDE acrivity. These areas are not required to NDE methods development but have potential to reduce cost, eliminate potential contamination, or improve the reliability of the remote NDE system.

- New developments in laser-generated and laser-received ultrasound.

- Developments in EMAT technology.

- Gas coupled ultrasound. 


\section{Appendix \\ The Ultrasonic Test Bed}

The Vltrasonic Test Bed (UTB) is a 14-axis robot with 1wo transducers capable of curvilinear motion especially suited to ultrasonic testing (liig. 23). This allows (wo) transducers to be manipulated arbitrarily with respect to each other within a limited cylindrical volume. One application for this robotic scanner is diffraction studies of scattering from materials and flaws.

The UTB is intended to allow developing complex ultrasonic methods without building complex robots [14]. It is also designed to allow scattered and diffracted ultrasonic fields to be easily measured. These two features make the UTB ideally suited to developing an ultrasonic method for the closure of the waste container.

Some of the UTB's unique capabilities:

- Simultaneous movement of the 14 axes.

- Collecrion of A, B and C-scan data while moving multiple axes.

- Coordinated movement of both uransducer manipulators while obtaining A, B, or Cscan data.

- Access to exisung signal-processing codes on the NDE VAX Cluster SAFT and others. Together these comprise approximately 100 image-processing and 50 time domain image-processing codes providing a rich environment for developing ultrasonic signal-processing codes.

- Ability to move both transducers allows modeling multi-transducer tests by placing multiple transducer arrays in each manipulator. Using pairs to simulate the movement of each pair of a more complex array is also possible. The movement of more than two transducers is currently regarded as the most complex method being considered for closure inspecion and simpler movement is desired. 


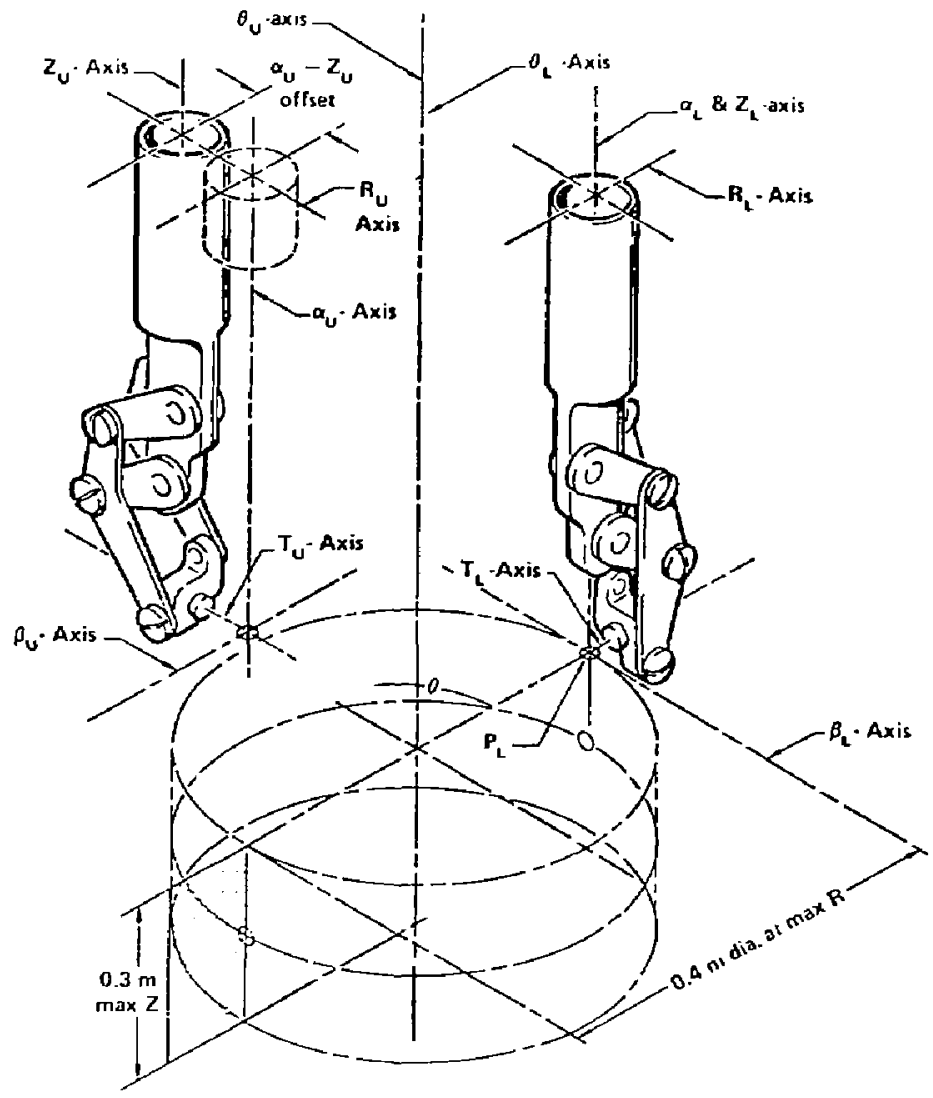

Figure 23. Motions of the ultrasonic test bed.

The UTB is not intended to be a model of a remote in spection system for the container closure examination but a means to define ultrasonic performance prior to building the closure inspection system. This role is specifically intended to reduce the complexity of the system that must be built to perform closure ultrasonic inspection. The tacit assumption that closure examination will not require a 14-axis system seems reasonable in light of the existing remote ultrasonic technology and the need for a reliable low-maintenance closure NDE system. 


\section{References}

I. U. S. DoE, Office of Civilian Radioactive Waste Management, Site Characterization Plan, Yucea Mountain Site, Nevada Research and Development Area, Nevada, 5 January 1987, Draft

2. H. Wustenberg, et. al., In-service Inspection of Nuclear Power Plant Components, IAEA-SM1$195 / 25,1975$.

3. A. Poularikas and W. Dandreta, Sratistical properties of acoustic waves in bounded media. J. Appl. Phys., Vol. 43, No. 8, August 1972, pp3578-3579.

4. P. Rogers and A. Van Buren, An exact expression for the Lommel diffraction integral, J. Acoust. Soc. Am., 55, pp 724-728, 1974.

5. ASME Bóler and Pressure Vessel Code, Section V, Nondestructive Examination, Aricle 6. Liquid Penetran Examination. 1986.

6. J. Reitz and F. Milford, Foundations of Electromagnetic Theory, Sccond Edition, 1967, Addison-Wesley, p305.

7. J. Perpechal, Remote Ultrasonic Testing of Nuclear Reactor Pressure Vessels, Skoda Review, No. 2. p22-31, 1983.

8. G. Herberg, W. Muller, O. Ganglebauer, First Experiences by Ulirasonic Tesling of Austenitic Stcel Welds, Specialists Meeting on UT of Reactor Components, United Kingdom, September 1976.

9. F. Becker, G. Dau, M. Behravesh, Piping Inspection Activities at the EPRI NDE Center, Nondestructive Evaluation Program: Progress in 1985, EPRI NP-4315-SR, May 1986.

10. S. Mech, J. Martin, Ultrasonic Inspection of Liquid Meral Filled Austenitic Slainless Steel Piping Welds, HEDL-SA-2665FP, May 6, 1982.

11. R. McClung, Report of Visit by R. J. Hudgell ra Oak Ridge National Labararory, October $15,1980$.

12. I. Deputat, J. Mazurek, and Z. Pawlowski, Uttrasonic sesting of brass castings, 6th International Conf. on Nondestr. Test., Hanover 1970, Vol. E, p87-98.

13. L. Paradis, Y. Serruys, and R. Saglio, A Time of Flight Method for Crack Evaluation Using Focused Ultrasonic Probes\}, Materials Evaluation, April 1986, Vol. 44, No. 5, p568-570.

14. I. Clark, Fabricarion of Inconel J82 Weldments Containing Inerdendritic Stress Corrosion Cracks, Nondestructive Evaluation Program: Progress in 1985, Electric Power Research Institute, EPRI NP-4315-SR Special Report, May 1986.

15. J. Brase, R. McKinney, K. Blaedel, J. Oppenheimer, S. Wong, and J. Simmons, An Automoled Ultrasonic Test Bed, Material Evaluation, December 1984. Vol. 42, No. 13, p1619-1625.

16. M. Silk, B. Lidington and G. Hiammond, A Time Domain Approach to Crack Location and Sizing in Austenitic Welds, British Journal of NDT, March 1980, Vol. 22, No. 2, pp55-61.

17. J. Ogilvy. Computer Utrasonic Ray Tracing in Austenitic Steel, NDT International, 18, 1985, p67-77.

18. J Opsal, Calculations of Elastic. Wave Scaltering from Voids und Crack-Like Defects by the Meshod of Optimul Trunration, Lawrence Livermore National Laboratory, UCRL-86333, 29 June 198I. 
19. W. Visscher, Elastic wave scattering by a surface-breaking or sulwarface plantar crack, J. of Applied Physics, 56(3), I August 1984, p713-725.

20. G. Thomas and N. Spinrad, Ultrasonic Strength Determination of Pinch Welds, Symposium of Solid State Bonding, Sandia Laboratorics, 1986.

21. H. Kraus, Generalized syntheric aperture, focused transducer, pulse-echo, ultrasonic scan data processing for non-destructive nspection, Ultrasonics, January 1983, pp1 1-18.

22. R. Hudgell, H. Seed, Ultrasonic Longitudinal Wave Examination of Austenitic Welds, British Journal of NDT, March 1980, Vol. 22. No. 2. pp78-85.

23. J. Gieske, G. Stoker, and P. Walkington, Sizing Defects Using Annular Array Techniques with an Automatic Ulirasonic Dara Acquisition System, Review of Progress in Quantitative Nondestructive Evaluation, Vol. 3A, 1984.

24. R. Day, Ultrasonic Examination and Inservice Inspection of LMFBR Transition Joint Welds, June 1983 ASME Pressure Vessel and Piping Conference, Portand, OR.

25. G. Clark, D. Tilly, B. Cook, and J. Brase, Bandlimited Signal Extrapolation for A-and B-Scan Resolution Enhancement, Quantitative Nondestructive Evaluation Conference, Williamsburg, VA, June 23-28, 1985.

26. D. Heinrich, G. Muller, and M. Weiss, Mechanized in-service ultrasonic inspection of austeniric welds in nuclear planis, Ultrasonics, 1982.

27. J. Rose, G. Singh, A Pattern Recognition Reflector Classification Feasibility Ssudy in Ultrasonic I nspection of Siainless Steel Pipe Welds, British Journal of NDT, November 1979, pp308-311.

28. I. Bell and B. Gray, Developments in the UK on Ultrasonics for Austenitic Steel Weldments, Seminar on NDE in Relation to Structural Integrity, Paris 24-25, August 1981.

29. M. Silk, A computer model for ultrasonic propagation in complex orthotropic siructures, Ultrasonics, SepL 1981, pp208-213.

30. B. Baikie, A. Wagg, M. Whitle, and D. Yapp, Ultrasonic Inspection of Austenitic Weids, IAEA, IWGFR Meeting on In-service inspection, Bensberg. March 1976.

31. M. Silk and B. Lidington, The potential of scattered or diffracted ultrasound in the determination of crock depth. Nondestructive Testing, Junc 1975, ppl46-151.

32. L. Busse, H. Collins, S. Doctor, Review and Discussion of the Development of Synthesic Aperture Focusing Technique for Ultrasonic Testing (SAFT-UT), NUREG/CR-3625 PNL-4957, March 1984.

33. J. Frederick, R. Fairchild, B. Anderson, Improved Ultrasonic Nondestructive Testing of Pressure Vessels, NUREG-0007-2, NRC-5, Sept. 1977.

34. B. Barna and J. Iohnson, The Effects of Surface-Mapping Corrections and Synthetic-Aperture Focusing Techniques of Ulirasonic Imaging, EGG-FM-5314, EG\&G Idaho Falls INEL, January $198 \mathrm{~L}$.

35. P. Corl, F. Grant, G. Kino, A Digital Synthetic Focus Acoustic Imaging System for NDE, 1978 IEEE Ultrasonics Symposium Proceedings, pp263-268.

36. M. Moles and J. Imada, Ultrusonic Inspection of Candidate Used Fuel Container Weld Materials, Alomic Encrgy of Cáada Lid., TR-321, Seplember 1985. 
37. N. Batra and H. Chaskelis, Determination of minimun faw size delecuble by ulirasonics in tiranium alloy plates, NDT International. Vol. 18, No. 5, October 1985.

38. S. Ganapathy, et al, Design and Development of a Special Purpose SAFT Sysrem for Nondestructive Evaluation of Nuclear Reactor Vessels and Piping Components, NUREG/CR-4365.

39. S. Ganapathy, ef al, Investigation of Special Purpose Processors for Real-Time Syntheric Aperturc Focusing Techniques For Nondesiructive Evaluation of Nuclear Reacror Vessels and Piping Componenis, NUREG/CR-2703.

40. J. Polky and D. Miller, An Ulira-Nigh Speed Residue Processor for SAFT Inspection System Imwge Enhancement, NUREG/CR 4170.

41. D. Hamlin, Program for Field Validation of the Synthesic Aperture Focusing Technique for Ulirasonic Testing (SAFT UT). NUREG/CR 4078.

42. S. Doctor, T. Hall, and L Reid, SAFT - The Evolution of a Signal Processing Technology for Ulirasonic Testing, March 1986, to be published in NDT International.

43. S. Doctor, 3. Crawford, and T. Hall, SAFT-UT Field Experience, Proceedings of the 1985 Pressure Vessels and Piping Conference, Residual-Life Assessment, Nondestructive Examination, and Nuclear Hear Exchanger Maserials, PVP.Vol. 98-1. 